\title{
TECNOLOGÍA Y MÉTODOS PARA EL DESBASTE DE LASCAS EN EL NORTE DE TIERRA DEL FUEGO: LOS NÚCLEOS DEL SITIO CABO SAN VICENTE ${ }^{1}$
}

\author{
FLAVIA MORELLO R. ${ }^{2}$
}

\begin{abstract}
RESUMEN
Desde una perspectiva tecnológica se aborda el estudio de la Colección Cabo San Vicente I, recolectada por Annette Laming-Emperaire en 1959 en la costa norte de Tierra del Fuego, Patagonia - Chile. A partir de un estudio detallado de los núcleos, se busca abordar la problemática de los sistemas de desbaste líticos como conjunto de acciones planificadas dentro de un contexto cultural mayor. Primero, se identifican y reconstruyen los esquemas operatorios de desbaste para discutir los conceptos técnicos empleados en su ejecución. Segundo, se intenta caracterizar los soportes potenciales, o productos, de los sistemas de desbaste a partir de su secuencia de producción. Los resultados del estudio permiten identificar cuatro métodos de desbaste de lascas: un método tipo Levallois, un método unipolar de extracciones secantes a partir de lascas gruesas, un tercer método en tajadas sobre yunque, y un último sistema de desbaste discoideo. Se discute la interrelación de estos cuatro métodos a la luz de la disponibilidad de materias primas, las secuencias de retomado de núcleos, y las evidencias de una estrategia técnica expeditiva en Cabo San Vicente. Por último, se plantea el desarrollo de una economía de desbaste basada en el concepto Levallois y su carácter versátil o polivalente, considerándolo como un método de producción integrado de soportes diferenciales.
\end{abstract}

PALABRAS CLAVES: Tierra del Fuego, Patagonia, tecnología lítica, Levallois, desbaste.

\section{TECHNOLOGY AND FLAKE OBTENTION METHODS IN THE NORTH OF TIERRA DEL FUEGO: THE CORES OF CABO SAN VICENTE SITE}

\footnotetext{
ABSTRACT

This study examines lithic material from the Cabo San Vicente I collection from a technological perspective. This collection, composed of material from the north coast of Tierra del Fuego island, Patagonia - Chile, was put together by Annette Laming-Emperaire in 1959. The study presented here focuses on lithic cores by approaching

1 Basado en la tesis de Master - Junio, 2004 - Caractérisation Technologique des Chasseurs Terrestres de L'Holocène Récent en Terre de Feu (Patagonie): Le Témoignage des Nucleus de Cabo San Vicente. Mémoire DEA Préhistoire - Ethnologie - Anthropologie, UNIVERSITE PARIS I Panthéon- Sorbonne, U.F.R.03 Histoire de l'Art et Archéologie. Directora: Nicole Pigeot. Tutora: Dominique Legoupil.

2 Centro de Estudios del Hombre Austral, Instituto de la Patagonia, Universidad de Magallanes y Centro de Estudios del Cuaternario de Fuego-Patagonia y Antártica (CEQUA), Universidad de Magallanes. Av. Bulnes 01890, Punta Arenas, Chile. E-mail: fmorello@aoniken.fc.umag.cl.
} 
their reduction sequences as planned actions within a broader cultural framework. First, the study identifies core reduction systems in order to discuss the key technical concepts that frame specific sequences. Second, the study attempts to characterize the potential supports or products by examining their production sequences. The results of the study enable a distinction between four methods of core reduction geared to the production of useful flakes: a Levallois-like method, a unipolar secant technique on thick flakes, a method of flake slices on anvil, and a discoidal core reduction method. These results are discussed by considering the relations between these four methods in view of raw material availability, sequences of core reuse, and evidence of an expedient technical strategy at Cabo San Vicente. Finally, the development of a core reduction economy, based on the versatility of the Levallois concept as an integrated technique that produces different types of supports, is postulated.

KEY WORDS: Tierra del Fuego, Patagonia, lithic technology, Levallois, core reduction (débitage).

\section{INTRODUCCIÓN}

Los fueguinos han habitado la isla grande de Tierra del Fuego al menos desde finales del Pleistoceno hasta los inicios del siglo XX, remontándose su aislamiento geográfico al Holoceno temprano, con posterioridad a los 9.000 años AP (Clapperton 1992). Los cazadores recolectores históricos conocidos como Selk'nam, representan un problema interesante ya que las descripciones etnográficas de estos grupos se realizan ya en un estado avanzado del proceso de aculturación, y se trata mayoritariamente de informantes indígenas del sector sur de la isla, que vivían presionados y acorralados en la zona boscosa.

Para conocer los grupos que habitaban la zona norte queda principalmente el registro arqueológico, en muchos casos más rico y detallado que los datos etnográficos en aspectos de tecnología lítica y economía, sin contar la mayor profundidad temporal de éste, y otros aspectos relacionados con la cultura material.

La arqueología muestra diferencias y similitudes entre las sociedades prehistóricas y los distintos grupos etnográficos, indicios que plantean la problemática de la existencia de diferentes grupos socioculturales en el curso de la prehistoria, sus procesos de cambio y de su adaptación a los distintos medio ambientes de la isla.

En un esfuerzo por comenzar a caracterizar el subsistema tecnológico de los cazadores recolectores terrestres de Tierra del Fuego, específicamente el rol que cumplen en él las industrias líticas de la piedra tallada, nos hemos propuesto abordar el tema de los sistemas de desbaste. El desbaste se define como el fracturamiento de la materia prima lítica para obtener soportes de instrumentos (Inizan, et al. 1995).
Representa una parte del subsistema tecnológico de toda sociedad, y por lo tanto se encuentra integrado al sistema sociocultural (Lemonnier 1991).

Como primera aproximación a esta problemática, se presenta el estudio de un conjunto de núcleos recolectados en Cabo San Vicente, península Juan Mazía, por la Misión Arqueológica Francesa en 1959. Este material lítico nos ha permitido reconstruir una parte de la cadena operatoria del desbaste de lascas puestas en juego por los grupos que habitaron la zona norte de la isla de Tierra del Fuego, describir los comportamientos tecnológicos que nos permiten discutir la presencia de tradiciones culturales y la implantación de estrategias tecnoeconómicas propias de estos pueblos, o al menos particulares a los grupos que habitaron la zona durante el Holoceno tardío.

\section{MARCO TEÓRICO Y PROBLEMÁTICA}

Los antecedentes existentes sobre las industrias líticas de cazadores recolectores terrestres de Tierra del Fuego son predominantemente de carácter tipológico, por sobre otros de enfoque tecnológico (Jackson 2002) y de materias primas (Franco y Borrero 1999; Ratto y García 1996). No obstante, quisiéramos destacar ciertos estudios tecnológicos desarrollados por Hugo Nami (1988) y Donald Jackson (2002). El primero hace mención, por primera vez, a la presencia de desbaste Levallois en la isla, en el sitio Rancho Donata (península Mitre) que presenta un fechado tardío entre aproximadamente 1.500 y 1.800 años AP (Nami 1992). También este tipo de talla fue descrito por Luc Vallin en Estancia Viamonte (Vallin 1992). En ambos casos se trata de núcleos Levallois de lasca preferencial registrados en 
sitios caracterizados como talleres líticos, al menos en parte, y localizados en la costa sudeste de Tierra del Fuego. En el sitio de Tres Arroyos 1, el estudio de los materiales líticos de las capas de ocupación temprana (ca. $10.500 \mathrm{AP}$ ), permitió registrar el uso de un conjunto interesante de técnicas de aplicación de la fuerza de extracción, como la percusión dura, la percusión blanda en la talla bifacial, la presión y la percusión bipolar o sobre yunque. También llama la atención la observación de la técnica de golpe de buril. En dicha ocupación sólo se registró un núcleo sobre madera fósil, pero no existe una descripción detallada sobre el sistema de desbaste (Jackson 2002). Por último, quisiéramos mencionar la investigación sistemática que hace años lleva a cabo Hugo Nami sobre la talla bifacial de puntas de proyectil. Esta se basa en el análisis de materiales arqueológicos y estudios experimentales (Nami 1988, 1992-93).

Entonces, es poco lo que conocemos sobre los sistemas de desbaste u obtención de soportes entre los grupos terrestres de Tierra del Fuego. Es evidente que la mayor parte de este tipo de talla está enfocada a la obtención de soportes del tipo lasca, aparte de la mención anecdótica de la presencia de núcleos Levallois.

Desde una perspectiva tecnológica es relevante el estudio detallado de los sistemas de desbaste líticos implementados por las sociedades prehistóricas, en tanto representan acciones planificadas dentro de un cuadro cultural. Esta caracterización de los sistemas de desbaste es parte integral de la comprensión y caracterización de los instrumentos líticos, entendidos como medios de acción sobre la materia (Inizan et al. 1995), elementos que deben ser aprehendidos en su relación a las tecnologías de adquisición y consumación de una sociedad (Leroi-Gourhan 1943). Estos aspectos también permiten considerar los sistemas de desbaste y talla en general como elementos del sistema sociocultural de un grupo, de una cultura material particular (Lemonnier 1983, 1991) y situada en el tiempo y en el espacio. Es la interacción de los elementos tecnológicos (los métodos utilizados, su frecuencia, riqueza y distribución) y otros de carácter social, espacial, económico, etc. (la organización de la movilidad anual, la distribución espacial de las actividades, la organización de la obtención de recursos, entre otros) que pueden llegar a ser característicos de un grupo cultural, y no solamente la presencia de un rasgo tecnológico aislado, como por ejemplo el desbaste Levallois. La discusión de las restricciones naturales, técnicas y económicas debe expresarse antes de evaluar la pertinencia del factor cultural y la tradición cultural, así como las elecciones preferenciales puestas en obra en este aspecto del subsistema tecnológico. Es decir, exponer la interrelación entre la producción de soportes y otros aspectos del sistema cultural (Pigeot 1991). En general, como es evidente, toda esta propuesta teórica-metodológica se basa en la orientación de la escuela francesa de estudios tecnológicos.

La problemática general de este estudio es la técnica de desbaste de los grupos prehistóricos de la isla grande de Tierra del Fuego, técnica entendida como un sistema de producción de soportes, artefactos que pueden por sí mismos ser utilizados como portadores de filos naturales o productos posteriormente formalizados por retoque. Como primera aproximación, hemos abordado el análisis de una colección de más de 1200 piezas líticas, esencialmente instrumentos retocados, bifaces y núcleos, del sitio Cabo San Vicente. Entre los materiales se han seleccionado los núcleos para un estudio detallado. Como lo ha destacado el arqueólogo Eric Boëda, todo desbaste está regido por un conjunto de criterios técnicos específicos, de consecuencias conocidas y buscadas, [y] el núcleo portador del conjunto de esta estructura constituye el mejor elemento para reconocer el sistema de producción lítica adoptada (Boëda 1994)․․ Además, los núcleos portan información dinámica sobre las grandes líneas que articulan las cadenas operatorias técnicas (Pigeot 1991); muestran la materialización de los comportamientos para la obtención de soportes y entregan, igualmente, a partir de los negativos de estos soportes, información sobre los productos deseados o buscados, a pesar de las limitaciones evidentes del estudio parcial de sólo una parte de la industria lítica de un sitio ${ }^{2}$. En el conjunto, las recu-

1 Traducción de la autora. Texto original: "tout débitage étant régi par un ensemble de critères techniques spécifiques, aux conséquences connues et recherchées, le núcleos porteur de l'ensemble de cette structure constitue le meilleur élément pour reconnaitre le système de production lithique adopté" (Boëda 1994: 265).

2 En este sentido, en futuros estudios, será de interés estudiar la diversidad de artefactos de un sitio, los instrumentos, desechos y otros que puedan permitirnos una reconstrucción más exacta de las elecciones efectuadas y de la conducta involucrada. 
rrencias que esperamos registrar serán indicadores de las elecciones preferenciales, y la variabilidad observada podrá ser discutida de diferentes maneras, en relación a restricciones naturales o culturales, técnicas, económicas, sociales, etc.

La noción de cadena operatoria, desarrollada por André Leroi-Gourhan, es un pilar fundamental en el marco teórico que se maneja. Consiste en un seguimiento de las trayectorias de transformación tecnológica que sufre la materia prima bruta hasta convertirse en un producto terminado, y ser finalmente abandonado. Este seguimiento permite trazar las operaciones efectuadas, los medios de acción y el conocimiento utilizado (Schlanger 2005).

En este contexto, visualizamos la problemática a través de dos objetivos específicos:

- Identificar los sistemas de desbaste utilizados por los grupos que habitaron el sitio Cabo San Vicente. ¿Las normas registradas en los núcleos son rígidas o flexibles, su cambio es oportunista o planificado? ¿Hay alguna relación evidente con otros aspectos de la cultura prehistórica de estos grupos? Estas preguntas serán abordadas a través de la reconstrucción de los esquemas operatorios de desbaste y una discusión sobre los conceptos puestos en obra para su desarrollo material. Esta discusión se basará también sobre las normas (recurrencias) registradas en el conjunto de núcleos y su grado de variabilidad.

- Caracterizar los soportes potenciales o productos de los sistemas de desbaste, y su secuencia de producción. ¿Se observan recurrencias, cuáles son los productos preferentemente buscados? Esta discusión y su relación con las estrategias tecnoeconómicas nos permite llegar a las problemáticas de una economía del desbaste o una economía de materias primas (Perlès 1991).

\section{METODOLOGÍA}

La colección de Cabo San Vicente es rica en artefactos e instrumentos, aunque el presente estudio se centra en los núcleos. El material fue ordenado, primero, según cuatro categorías generales: piezas retocadas, artefactos de talla bifacial (façonnage), núcleos y desechos. Al respecto nos parece necesario aclarar que se tradujo debitage del francés como desbaste y no talla, por ser un concepto más específico y en tanto término con- trario de façonnage. El desbaste es la acción de fraccionar la materia prima con el fin de obtener soportes, se utiliza solamente en caso de productos obtenidos intencionalmente por percusión o presión, y permite dividir los restos líticos en núcleos y derivados de núcleos (Inizan et al. 1995). Hasta el momento no se ha encontrado un término en español que traduzca por completo el significado de façonnage, por lo que se mantiene la palabra francesa al igual que se ha sugerido en otros casos (Legoupil 2003). El concepto de façonnage se reserva para una sucesión de operaciones de talla en donde el objetivo es fabricar un objeto, y uno sólo, tallando la materia prima según una forma deseada. Este modo de talla se puede insertar en cualquier fase de una cadena operativa, y su fin es generar una morfología específica. Aunque se aplica esencialmente a objetos bifaciales, también concierne a otros artefactos como las hachas y boleadoras, y la fabricación de preformas, entre otros casos. Se podría agregar que el término implica moldear un soporte a través de diversas etapas de formatización, que pueden incluir distintas técnicas de talla. No obstante, si una operación que pertenece al façonnage de una pieza resulta, luego de un análisis comprehensivo, formar parte de una cadena operativa de desbaste, se habla entonces de puesta en forma del núcleo, pues la intención y el concepto son diferentes (Inizan et al. 1995).

Considerando los núcleos como la evidencia más rica en información, y debido a la escasez de restos brutos de talla en Cabo San Vicente, el presente estudio se centró principalmente en los primeros. Sin embargo, una muestra del 26\% de la colección fue analizada para evaluar la representatividad de las categorías generales, y en conjunto con los núcleos, esta muestra permitió caracterizar las materias primas explotadas en el sitio.

La identificación y caracterización de los núcleos fue efectuada de manera progresiva, una primera separación consideró todas las piezas sobre masa central que presentaban solamente negativos. Luego, un segundo criterio fue el registro de negativos de extracciones potencialmente compatibles con algunos de los soportes de instrumentos manufacturados sobre lascas y las escasas láminas retocadas presentes en la colección. Algunos fragmentos poco claros fueron excluidos por no ser determinables. Con respecto al segundo criterio implementado, este 
permitió distinguir dos grandes conjuntos de núcleos indeterminados, no excluyentes entre sí:

- Un número considerable de piezas bifaciales no entra claramente ni en la categoría de piezas de talla bifacial o façonnage, ni en el conjunto de núcleos.

- Una serie de artefactos sobre masa central, inicialmente considerados núcleos, fueron considerados indeterminados en razón de la organización de las extracciones, pues pueden considerarse tanto como núcleos, instrumentos (o preformas no bifaciales) o ambos a la vez.

Se desarrolló un tercer criterio para separar los percutores identificados a partir de sus aristas y bordes con fuertes esquirlas y abujardados o triturados. Algunas de estas piezas presentaban lascados accidentales medianamente extendidos pero sin ninguna organización evidente, excepto su asociación y desprendimiento a partir de los bordes con marcas de trituramiento y percusión insistente. Estas piezas han sido consideradas como percutores sobre arista (total 9 piezas).

La metodología de estudio de los núcleos consistió en una primera clasificación general con relación a la organización de los negativos, los planos de percusión y la orientación de las extracciones con respecto a su plano de fracturación o eje tecnológico: secante o paralelo. Estas variables han sido consideradas como pertinentes en otros estudios tecnológicos de colecciones de Patagonia, específicamente en el sitio Ponsonby el desbaste paralelo al plano del objeto (desbaste expandido) y el desbaste secante [...]. El desbaste paralelo es la solución para obtener grandes piezas como en el Levallois, porque es expandido; el desbaste secante es la mejor solución para desbastar "fácilmente", incluso de manera abundante, pues las restricciones de ángulo, de convexidad y de reflexión son entonces menores. La contraparte es que los productos son más cortos, más gruesos y de forma menos normalizada (Pigeot 2003). Luego, cada pieza fue sujeto de una lectura detallada a partir de su esquema diacrítico, lo que permitió la descripción de los métodos de desbaste recurrentes y la definición de criterios tecnológicos de identificación. Los conjuntos de núcleos, clasificados según método de desbaste, fueron analizados por grupo en relación a las variables consideradas pertinentes para caracterizar la coherencia y variabilidad al interior de cada método y su producción. Algunas variables comunes a los métodos de desbaste registrados permiten comparar los sistemas en función de la dimensión de los productos y su morfología.

Por método de talla se entiende una gestión técnica que generalmente incluye un proceder razonado y con una cierta cantidad de gestos ejecutados cada uno gracias a una o varias técnicas de aplicación de la fuerza. Es decir, su identificación está basada en el registro recurrente de gestos sucesivos, ligados a una técnica y una organización particular de las extracciones. El término de método de talla (desbaste o façonnage) implica generalmente la existencia de un esquema conceptual elaborado ${ }^{3}$, una especie de modelo, idea o imagen mental, conducente a la obtención de productos predeterminados y que guía las acciones y la sucesión recurrente de gestos técnicos. Es esta intención la que debe tratar de desentrañarse a través de los vestigios materiales y su análisis (cfr. Inizan et al. 1995), llegando a través del método, al concepto que existe detrás de los gestos técnicos y así a las conductas culturalmente aprendidas y transmitidas en una sociedad o grupo humano.

El esquema diacrítico es un tipo de diseño esquemático de una pieza, que permite mostrar de manera simple la concatenación de los últimos gestos que condujeron al estado de abandono del artefacto. Sólo reproduce el contorno de la pieza, las aristas y nervuras con las extracciones y fragmentos visibles. La dirección, sentido y cronología de las extracciones son indicadas con flechas numeradas, y la presencia de bulbo (talón) o contra-bulbo son indicadas con un punto en la base de la flecha respectiva. El esquema diacrítico generalmente permite reconstruir una parte o varias de una cadena operatoria (Ibíd).

En fin, entre los criterios registrados para cada método de desbaste identificado, se consideró la técnica de aplicación de la fuerza. Entre las técnicas clásicas conocidas se pudo observar el uso de percusión directa dura y percusión sobre yunque. La percusión sobre yunque a veces también ha sido denominada bipolar, por la dinámica física que genera dos fuerzas que se ejercen al mismo tiempo en los extremos de la pieza. No obstante, consideramos más claro utilizar el término "percusión

3 Para los casos de métodos de talla no elaborados véase Inizan et al. 1995. 
sobre yunque", y reservar el concepto bipolar para el fraccionamiento de pequeños guijarros, un desbaste de tipo semi-controlado y también conocido como piezas de extremos esquirlados (pièce esquillée) y split (Brézillon 1983; Leroi-Gourhan 1988).

\section{CABO SAN VICENTE: EL SITIO ARQUEOLÓGICO}

El cabo San Vicente se localiza en la costa de bahía Lee, estrecho de Magallanes, en el extremo noroeste de la península Juan Mazía (Figs. 1 y 2). El sitio fue descubierto por Annette Laming-Emperaire y la Misión Arqueológica Francesa en el año 1959, y re-visitado posteriormente (1964). Ella misma lo describe como un gigantesco conjunto que se extiende por cerca de $5 \mathrm{~km}$ de largo (Laming-Emperaire 1972). La información manuscrita disponible señala que el sector fue subdividido en dos grandes sitios arqueológicos, presentando diferentes concentraciones de restos arqueológicos. El estudio concierne a Cabo San Vicente I, colección depositada en el Museo del Hombre en París, y recolectada en 1959 por A. Laming-Emperaire y $\mathrm{H}$. Reichlein. Incluye solamente recolecciones superficiales selectivas.

El yacimiento también fue revisitado en 1981, en el marco de prospecciones desarrolladas por Mauricio Massone en cabo San Vicente y bahía Lee. El sitio Cabo San Vicente I correspondería al

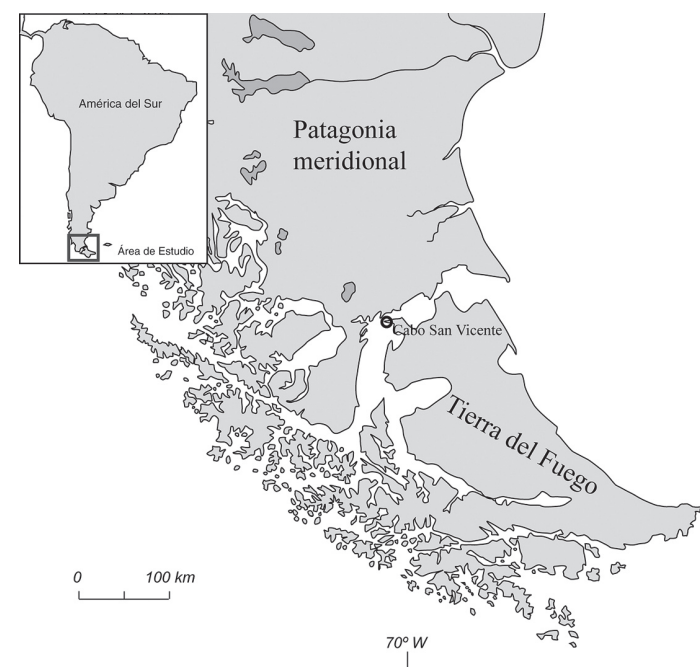

$50^{\circ} \underline{\mathrm{S}}$

Fig. 1. Mapa del área de estudio, en el que indica la ubicación de Cabo San Vicente, Tierra del Fuego. sitio Bahía Lee 3 de Massone, el cual fue sujeto de una recolección superficial sistemática de 10 x 5 m (com. pers. Mauricio Massone 2003). Este material depositado en el Centro de Estudios del Hombre Austral, del Instituto de la Patagonia (Universidad de Magallanes), será analizado en futuros estudios. Una fotografía publicada en dicha ocasión muestra la zona del sitio fotografiada por H. Reichlein en 1964 - Fig. 4 (Massone 1982). Además, en los últimos dos años, se ha retomado esta prospección, registrándose en detalle la zona y realizándose algunas excavaciones de sondeo (Massone 2004).

El sector donde se encuentra el sitio, el cabo, está rodeado de acantilados costeros. El yacimiento Cabo San Vicente I se ubica en una zona de terrazas, cercanas a una laguna estacional. Annette Laming-Emperaire observó la presencia de tres niveles de terrazas, las que fueron utilizadas como unidades de diferenciación espacial en el trabajo de recolección superficial y luego en algunos sondeos de excavación.

La terraza baja tendría aproximadamente 2 msnm (Laming-Emperaire 1959-1960). Un estudio geomorfológico de la zona (De Muro et al. 1996), en combinación con lo registrado por A. LamingEmperaire, nos permite establecer que esta terraza está relacionada con la playa actual de arenas y guijarros. Su formación es reciente y necesariamente posterior a los 5.000 años AP (Fig. 3).

La terraza media corresponde a una formación marina de la máxima trasgresión del Holoceno medio, datado en la zona entre 6.000 y 7.000 años AP:

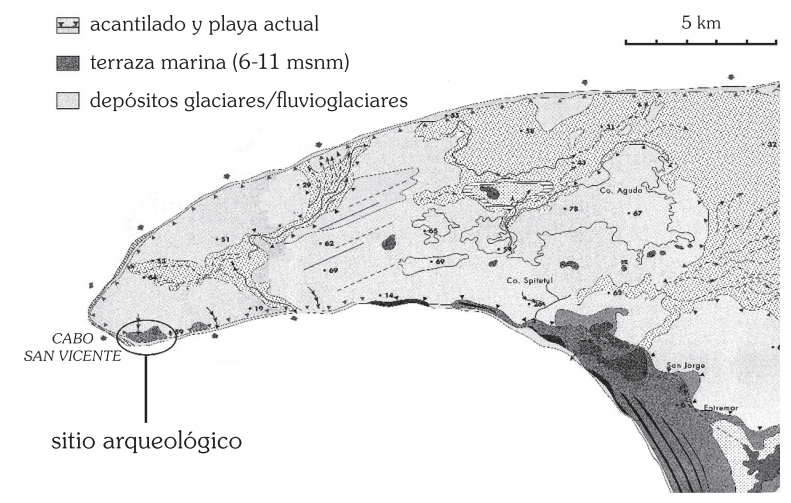

Fig. 2. Mapa de detalle del cabo San Vicente y la ubicación del sitio arqueológico (adaptado de De Muro et al. 1996). 


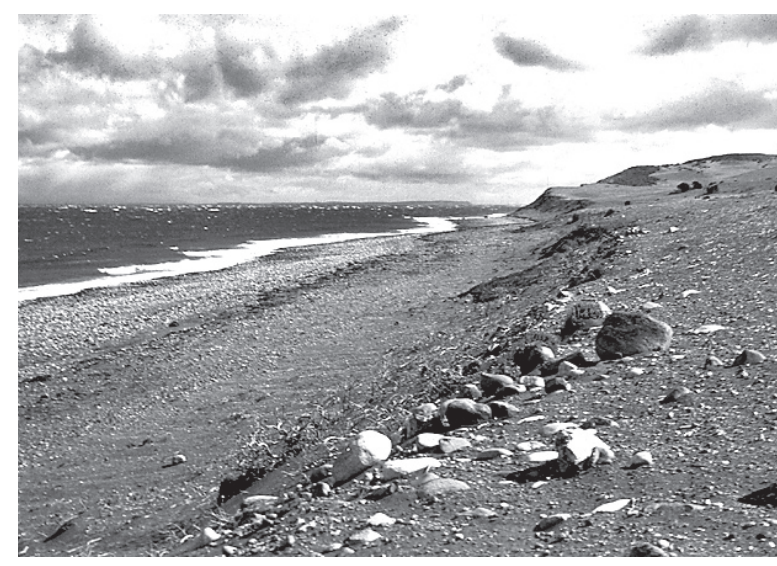

Fig. 3. Vista de la terraza baja del sitio Cabo San Vicente I (fotografía de H. Reichlein, 1959).

se localiza entre 6 y 11 msnm (Ibíd.). Esta terraza es la más extensa y comprende la mayor extensión del sitio (Fig. 4).

Por último, la terraza alta de A. Laming-Emperaire podría corresponder a dos geoformas. Por un lado, el estudio de De Muro et al. (1996) indica la presencia de distintos niveles aterrazados asociados a la trasgresión marina del Holoceno medio en la localidad, lo que constituye una posibilidad. La segunda, podría ser la geoforma identificada como una planicie de depósitos glaciares y glacio-fluviales no diferenciables y relativamente antigua (UMG, alrededor de $24.000 \mathrm{AP})$, ubicada entre 18 y 25 msnm (Ibíd.).

En las fotografías tomadas por Henri Reichlein en 1959 (Figs. 3 y 4) se observa que la playa actual, así como los depósitos glaciares y glacio-fluviales de la terraza alta poseen fuentes potenciales de materias primas líticas en forma de guijarros.

En las excavaciones de sondeo realizadas en los años 1959 y 1964 lograron distinguirse dos niveles arqueológicos en estratigrafía, asociados a restos líticos, mauchos (Patella sp.) y huesos de guanaco sobre la terraza media (A. Laming-Emperaire, notas del cuaderno de terreno, 22 de diciembre de 1964, p. 173).

Distinciones estratigráficas fueron igualmente señaladas por Annette Laming-Emperaire en otros sitios de la costa norte de la isla de Tierra del Fuego: ella registra en Punta Catalina y Cabo San Vicente, entre otros sitios, dos capas sucesivas de culturas de la piedra tallada. Una más antigua que se caracteriza

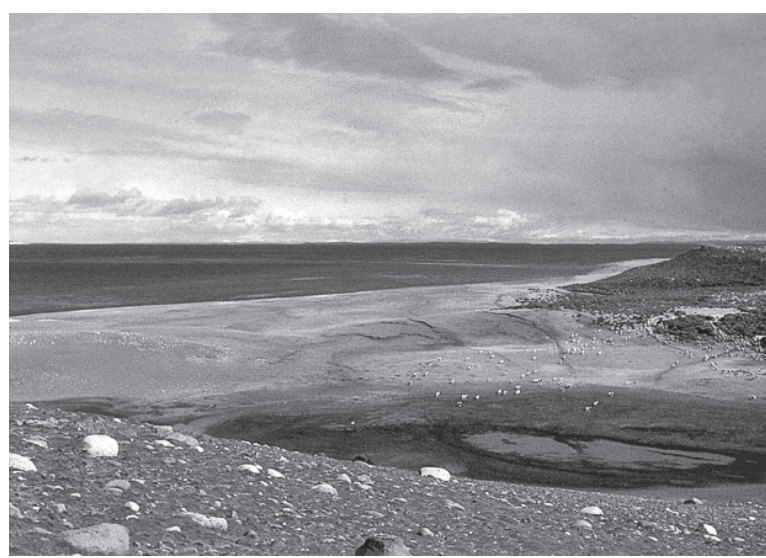

Fig. 4. La terraza media del sitio Cabo San Vicente I -incluyendo la laguna estacional- y parte de la terraza alta (fotografía de H. Reichlein, 1959).

por instrumentos grandes principalmente bifaciales, y una segunda capa, reciente, que se emparentaría a la industria lítica de los Onas de tiempos históricos (Laming-Emperaire 1959).

Se podría pensar que existen dos niveles principales en el sitio estudiado, pero estas diferencias nos han parecido demasiado vagas y complejas de evaluar en el estado actual del conocimiento. Aunque, no hemos logrado observar estas diferencias en el análisis de la colección, sí se han conservado las terrazas como principales unidades de estudio. A pesar de esto, hemos notado a partir del material lítico la presencia de ocupaciones múltiples (dos o más, si se considera la extensión del yacimiento) con una distancia temporal indeterminada y superposiciones espaciales evidentes. Ya sea que estas distinciones de capas representen grupos diferentes separados en el tiempo o variantes temporales y espaciales en las actividades y funciones realizadas por un mismo grupo en el sitio, la impresión de una diversidad de industrias líticas es un problema que sobrepasa las posibilidades actuales de estudio, pero este aspecto fue considerado indirectamente en el análisis.

4 De nombreux gisements (...) et quelques fouilles à Punta Catalina et au Cabo San Vicente permirent d'établir l'existence dans cette région de deux couches successives de cultures de la pierre taillée: l'une, la plus ancienne est caractérisée par un gros outillage essentiellement biface, l'autre, la plus récente, paraît s'apparenter davantage à l'industrie lithique des Onas des temps historiques (Laming-Emperaire 1959). 
Material: restricciones y ventajas

La colección de Cabo San Vicente I presenta una serie de problemas, de los cuales estamos concientes. La mayoría se debe al tipo de recolección (superficial) y a ciertas características del yacimiento. En razón del tipo de yacimiento, muy extendido y con una dispersión de concentraciones de diverso tipo, se puede suponer casi con certeza que es resultado de múltiples ocupaciones del lugar, probablemente a lo largo del Holoceno. Entonces es un sitio complejo, con depósitos que representan posiblemente un palimpsesto de estas ocupaciones, a juzgar por los procesos de erosión característicos del litoral norte de la isla en las últimas décadas. Por ejemplo, Annette Laming-Emperaire nota que la terraza alta, que conservaba aún cubierta vegetal en 1959, ya estaba totalmente erosionada en 1964 (A. Laming-Emperaire, notas del cuaderno de terreno, 22 de diciembre de 1964). A partir de estas observaciones y de las características del material lítico (diferentes niveles de pátinas) se puede estimar que los procesos de sedimentación y erosión sucesivas debieron tener y tienen consecuencias importantes en las condiciones de hallazgo y recolección de materiales arqueológicos.

La colección, presenta un problema de representatividad del conjunto debido a las características de la recolección, parcial y selectiva. Del conjunto se hace evidente que faltan los restos brutos de talla. La ausencia de estas piezas no permite hacer remontajes físicos y reconstituir integralmente ciertas cadenas operatorias, por lo que el análisis abre varias problemáticas que no se pueden resolver a partir de la colección Laming-Emperaire. Además, la selección entraña un sesgo hacia la recolección de instrumentos, generalmente artefactos grandes y piezas enteras (aproximadamente el $80 \%$ de los restos). Si esta selección representa lo mayoritario en el sitio o se debe al método de recolección, no es posible decirlo en este momento, pero sospechamos que la segunda posibilidad es más fuerte.

La selectividad de la recolección, no obstante, presenta también una gran ventaja: la gran cantidad de núcleos recolectados. Esta elección ha permitido abrir perspectivas de estudio tecnológico y evaluar las recurrencias y variabilidad del conjunto de esquemas operatorios puestos en obra a través del desbaste de estos núcleos.
La colección: generalidades y materias primas

La colección de Cabo San Vicente I comprende 1268 piezas, de las cuales 1265 son vestigios líticos ${ }^{5}$. Un total de 161 núcleos fueron identificados y analizados, lo que representa el 13\% de los materiales. La mayoría de los restos líticos provienen de la terraza media, 817 en total (65\%), otros 326 fueron recolectados en la terraza alta (26\%), y 125 piezas provienen de la terraza baja (9\%).

Para tener una estimación de la representación de las categorías generales en la colección, se han utilizado las frecuencias observadas en la terraza alta como muestra de análisis. En este caso, los núcleos suman el 8\% del material, los instrumentos sobre lasca son los predominantes con un 44\%, las piezas bifaciales llegan a una cifra importante de $26 \%$, los desechos de talla suman un $15 \%$ y luego se registró un $7 \%$ de indeterminados.

El análisis comparativo de las materias primas líticas presentes en el sitio se realizó a partir de la muestra (restos de la terraza alta) y la totalidad de los núcleos. Un primer aspecto a notar es la diversidad de rocas registradas, entre las cuales fue posible identificar un mínimo de ellas, como el basalto, la lutita silicificada, rocas silíceas, jaspe y madera fósil. No obstante, se diferenciaron un total de 32 tipos. Ninguna parece más representada que las otras, con sólo 4 conjuntos que superan levemente el 5\% del total. Solamente la materia prima № 5 (¿riolita?) destaca con una frecuencia del $20 \%$, pero a la vez es el grupo más heterogéneo.

No se observan preferencias por ninguna roca en particular. La selección de materias primas no parece responder al tipo de roca sino a una relación entre calidad y dimensión de los bloques. La calidad general de las materias primas es medianamente homogénea, generalmente de regular a buena (granos de dimensión mediana a fina) $)^{6}$. Pero, si se analiza la

5 Se registraron 3 piezas óseas sobre hueso de cetáceo que presentan trazas de cortes transversales y evidencia de pulido. Al menos uno de los fragmentos sería de mandíbula y los otros dos de costilla (com. pers. Dominique Legoupil 2004).

6 Hemos utilizado categorías relativas para la calidad: muy buena, buena, regular, mediocre y mala. Los criterios utilizados y su jerarquía son: dimensión de granos, presencia de impurezas (líneas de clivaje, cristales y otros), textura y aspecto silíceo de una roca. Todos estos criterios permiten evaluar la calidad de la roca en tanto su aptitud para la fractura concoidal. 
Tabla 1. Distribución espacial de núcleos según métodos de desbaste.

\begin{tabular}{|l|c|c|c|c|}
\hline $\begin{array}{c}\text { MÉTODO } \\
\text { (frecuencia y porcentaje por terraza) }\end{array}$ & Terraza alta & Terraza media & Terraza baja & TOTAL \\
\hline Levallois (36\%) & $8(14 \%)$ & $40(69 \%)$ & $10(17 \%)$ & 58 \\
\hline Unipolar secante sobre lasca espesa (11\%) & $4(22 \%)$ & $11(61 \%)$ & $3(17 \%)$ & 18 \\
\hline En tajadas sobre yunque y split (9\%) & 0 & $10(71 \%)$ & $4(29 \%)$ & 14 \\
\hline Discoideo (2\%) & $2(50 \%)$ & $2(50 \%)$ & 0 & 4 \\
\hline Indeterminados (42\%) & $12(18 \%)$ & $49(73 \%)$ & $6(9 \%)$ & 67 \\
\hline TOTAL & $26(16 \%)$ & $112(70 \%)$ & $23(14 \%)$ & 161 \\
\hline
\end{tabular}

calidad de las piezas al interior de los 32 grupos de rocas uno percibe que algunas presentan grandes variaciones en su interior, a veces desde muy buena a mediocre, en función de la dimensión de granos pero principalmente por la presencia de impurezas (líneas de clivaje) en los nódulos. La mayoría son nódulos del tipo guijarro o canto rodado (más del 90\%), pero hay unos pocos casos de bloques del tipo plaqueta.

El predominio de guijarros y la diversidad de rocas observada concuerda con los bloques presentes sobre la costa (terraza baja) y en los depósitos glacio-fluviales de la terraza alta, las dos son fuentes secundarias que se presentan a lo largo de toda la costa del estrecho de Magallanes. Estos aspectos nos permiten suponer que estas terrazas fueron la fuente de aprovisionamiento de las materias primas líticas del sitio Cabo San Vicente. No hay ningún elemento que permita pensar en un origen alóctono para alguna pieza. Es decir, independiente del sistema de desbaste implementado, las restricciones materiales pueden considerarse como reducidas y no involucrarían una inversión en el aprovisionamiento $y$ transporte de rocas no locales al sitio ${ }^{7}$. Por el momento la información de base no nos permite evaluar la relación entre los nódulos escogidos y la dimensión y morfología de los guijarros disponibles actualmente. En este sentido, ante la ausencia de relación entre métodos de desbaste y materias primas de características particulares, podemos señalar que no se implementó en Cabo San Vicente una economía de materias primas, en el sentido que Perlès lo señala (1991).

7 Algunas dudas surgieron ante ciertas piezas de madera fósil. Fuentes primarias de madera fósil han sido descritas en diferentes partes de la zona norte de Tierra del Fuego, pero también se han registrado fuentes secundarias en depósitos fluvio-glaciares dispersos en la isla (Jackson 2002) y especialmente en el litoral.

\section{LOS NÚCLEOS DE CABO SAN VICENTE: MÉTODOS Y PRODUCTOS}

El análisis tecnológico realizado sobre los núcleos de Cabo San Vicente I nos permitió distinguir cuatro métodos de desbaste (Tabla 1). El conjunto está compuesto de 161 núcleos, de los cuales se excluyeron los indeterminados. La representación de métodos es similar entre las tres terrazas, y la ausencia de núcleos discoideos y en tajadas sobre yunque en las terrazas baja y alta, respectivamente, parece más bien un problema de muestreo y cantidad de núcleos por terraza que una ausencia en el sitio. En general, los porcentajes de distribución de sistemas de desbaste por terraza son homogéneos. La presencia de tres de los métodos en la terraza baja nos permite tener un cuadro cronológico relativo para estos sistemas de desbaste, entre los 5.000 AP y el XVI siglo DC (terminus post quem sugerido por la ausencia de artefactos o desechos de vidrio y metal).

A continuación se tratará cada método por separado, viendo los criterios tecnológicos que los caracterizan y que soportan las reconstrucciones de los esquemas operatorios.

\section{MÉTODO LEVALLOIS}

El desbaste Levallois es el método más rico representado en el sitio, tanto por la cantidad de núcleos registrados como por los diferentes modos de explotación y modalidades observadas. En total 58 núcleos han sido tallados siguiendo este método definido tempranamente en las industrias líticas del Paleolítico medio en Europa. La utilización del nombre Levallois nos pareció justificado por la manera convencional en la que este método se presenta en el yacimiento. Desde su definición más clásica por parte de Bordes (1961, En Boëda 

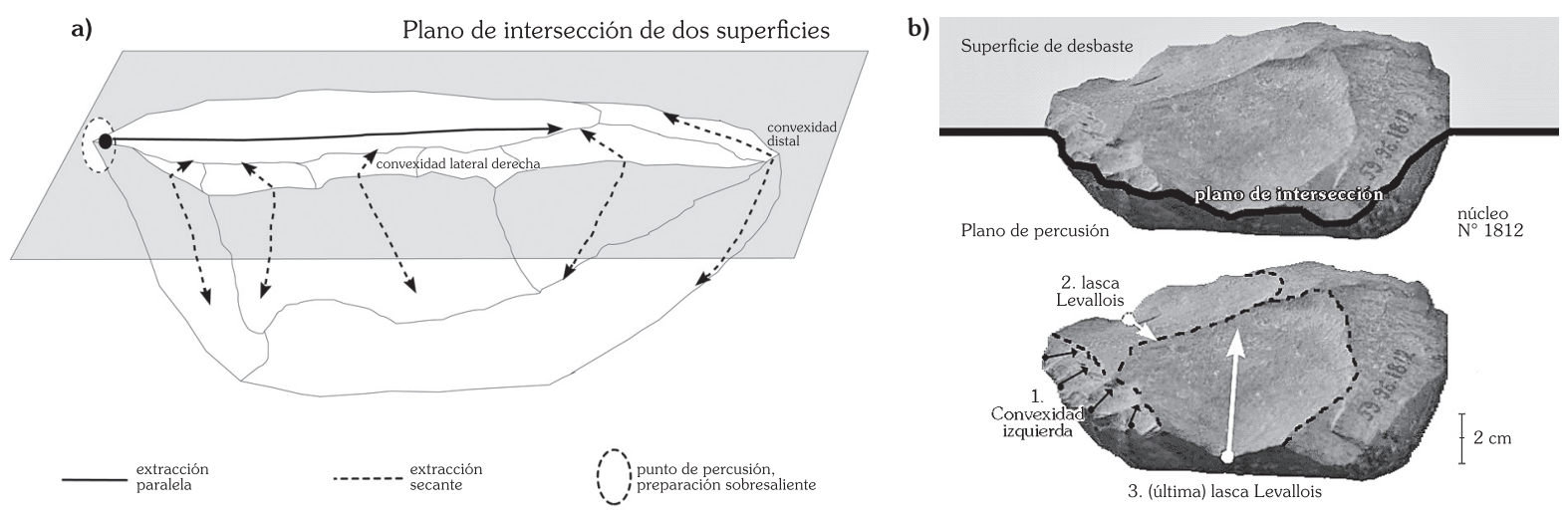

Fig. 5 a) Esquema indicando los criterios que caracterizan el método de desbaste Levallois lineal, b) Núcleo Levallois recurrente.

1994), se pensaba que este método permitía obtener formas predeterminadas de lascas, por medio de una preparación especial del núcleo. Los tipos de lascas predeterminadas registradas en esa época incluían la lasca Levallois, la punta Levallois y la lámina Levallois. Los núcleos eran preparados para generar una lasca cada vez, una lasca preferencial, lo que permite identificar el método como Levallois a lasca preferencial o también denominado método Levallois lineal. En la década de 1990, un estudio detallado sobre el método fue emprendido por Eric Boëda, lo que permitió re-evaluar las definiciones e identificaciones existentes, y estructurar las bases del concepto Levallois como principios que rigen la materialización del método. A través del estudio de materiales arqueológicos y el desarrollo de una experimentación sistemática logró definir una serie de criterios técnicos que identifican el método Levallois a partir de una concepción volumétrica del núcleo y sus modos de explotación. Además, identificó un segundo subtipo denominado método Levallois recurrente, cuyo objetivo es la obtención de varias extracciones predeterminadas de una misma superficie de desbaste, y no una sola lasca preferencial (Boëda 1994).

Los criterios tecnológicos que definen este método han sido puestos en evidencia a Cabo San Vicente por el análisis comparativo de los núcleos y esquemas diacríticos de cada pieza. Ellos indican la presencia de un conjunto de normas rígidas, observables sobre todos los núcleos que presentan marcas de una etapa de producción plena (total 54 núcleos), así como una serie de otros criterios frecuentemente observados pero negociables según el caso particular.
Cerca de la mitad de los núcleos identificados como desbaste Levallois están fundados sobre criterios claros y no presentan problemas de asignación. Algunos otros incorporados al conjunto presentan sólo algunos rasgos diagnósticos, y corresponden generalmente a piezas de historias complejas con diferentes secuencias de transformación y casos de núcleos retomados. Aunque puedan parecer discutibles, entran de manera coherente en el conjunto de núcleos Levallois. A continuación trataremos los criterios específicos que definen y caracterizan este método, los cuales fueron tomados y adaptados del estudio de Eric Boëda (1994).

1. La gestión del volumen del núcleo incluye dos superficies delimitadas por un plano de intersección imaginario. Las dos superficies están jerarquizadas según el rol que cumplen en una misma secuencia de producción, una corresponde a la superficie de desbaste y la otra al plano o plataforma de percusión (Fig. 5).

2. Se desarrolla un manejo de extracciones predeterminantes de ángulo secante con respecto al plan de intersección de las dos superficies, al menos sobre una superficie o ambas.

3. Las extracciones predeterminadas (lascas Levallois) deben presentar planos de fractura paralela o subparalela al plano de intersección, y una extensión invasiva o semi-extendida ${ }^{8}$ en la superficie

8 Se ha desarrollado esta variable con tres variantes que han sido aplicadas como un criterio homogéneo en los cuatro métodos descritos: invasor o extendido es una extracción (lasca o lámina) cuyo largo es superior al 50\% del largo máximo de la superficie de desbaste del núcleo (Boëda 1984), semi-extendido es aquel que tiene menos del 50\% y más del 30\% (un tercio) del largo de la superficie, y se considera como no extendido o marginal toda lasca cuyo largo es inferior al 30\% del largo de la superficie de núcleo. 
de desbaste. Estas extracciones predeterminadas, paralelas y extendidas, deben suceder o ser posteriores a las lascas predeterminantes secantes, en una misma secuencia de desbaste. Esta secuencia se observa claramente en los esquemas diacríticos.

4. La técnica de aplicación de la fuerza, tanto en las extracciones predeterminantes como aquéllas predeterminadas, es la percusión directa con percutor duro.

Algunos criterios, igualmente normativos e identificadores, pero negociables en diverso grado son:

5. Las dos superficies que generan la definición volumétrica del núcleo son de carácter asimétrico y convexo9 ${ }^{9}$ La asimetría de las superficies del núcleo puede verse suprimida por la gestión del volumen que hemos denominado "doble", y que se tratará más adelante. Lo que respecta a las convexidades de la superficie de desbaste, ésta se observa suprimida en algunos casos, es decir con una sección plana a cóncava, debido a la acumulación de extracciones predeterminadas o por el retomado del núcleo.

6. La preparación y manejo de las extracciones predeterminantes secantes, generando convexidades laterales y distales en la superficie de desbaste, permiten predeterminar los productos. Esto es, controlar las dimensiones y morfología de las lascas o láminas Levallois. La observación de convexidades laterales y distales secantes es frecuente en la colección: sobre 47 núcleos (81\%) se observa todavía restos de la preparación de las convexidades laterales, es decir, extracciones secantes, anteriores y en posición lateral (izquierda y/o derecha) con respecto a las extracciones predeterminadas paralelas. La ausencia aparente de la preparación de las convexidades se explica por la desaparición de las marcas por extracciones posteriores como es el caso de las lascas Levallois que borrarían estas huellas de los gestos técnicos de predeterminación. Los núcleos estudiados presentan todos los niveles de preservación de extracciones predeterminantes secantes, total, parcial, marcas mínimas (fragmentos de negativos secantes) o totalmente ausente. La preparación de la convexidad distal se registró solamente en

9 En algunas piezas se utiliza la convexidad natural del bloque, generalmente como superficie inferior o plano de percusión (7\% de los núcleos).
26 núcleos $(45 \%)^{10}$; esta disminución se explica por el modo de explotación Levallois que no es a lasca preferencial, es decir el método Levallois recurrente, que permite una gestión de la superficie de desbaste organizando más de una extracción extendida o semi-extendida por secuencia de desbaste. En estos casos, los negativos de las lascas predeterminadas anteriores, en una misma secuencia o de una más antigua, pueden borrar la convexidad distal (si existió) o hacerla innecesaria ya que esta función predeterminante puede ser reemplazada por el uso de los bordes y aristas de estas lascas Levallois anteriores como nervuras guías (observado en 35 núcleos, 60\% de los casos). Estas nervuras guías también pueden reemplazar en parte a las convexidades laterales, y son importantes en la predeterminación de las lascas Levallois ${ }^{11}$.

7. Las extracciones predeterminantes del plano de percusión son secantes por definición, y en algunos casos semi-extendidas e invasoras (62\%, 36 núcleos). Estas lascas tienen una dimensión y una morfología potencialmente apropiadas para su uso como soportes, similares a los productos del método de desbaste unipolar secante sobre lascas espesa, que será descrito más adelante. La pregunta de si se trata de productos, sub-productos o desechos será abordada en la discusión.

8. El plano de percusión es preparado de manera de estar próximo a perpendicular al plano de intersección de las dos superficies del núcleo. En un $40 \%$ de los núcleos se registra un procedimiento de preparación del plano de percusión que consiste en generar una prominencia, desde ligera a marcada, y delimitar mejor el punto de percusión. Este procedimiento está formado por dos negativos que forman una arista en el plano de percusión (talón del tipo diedro) y sus negativos son convergentes en la mitad de los casos. Es un procedimiento de preparación similar al que genera la preparación del talón "sombrero de gendarme" (chapeau de

10 En general, la organización de las lascas predeterminantes de las convexidades laterales y distales son centrípetas en su organización (47\%). También se observaron otros casos de combinaciones del tipo convergente, perpendicular $y / 0$ paralelo $(16 \%) y$, por último, un conjunto de piezas sin registro o no determinables (38\%).

11 Sin embargo, debemos aclarar que no se registró evidencia de la utilización sistemática de nervuras guía para generar lascas de morfología particular como las puntas Levallois. 
a)

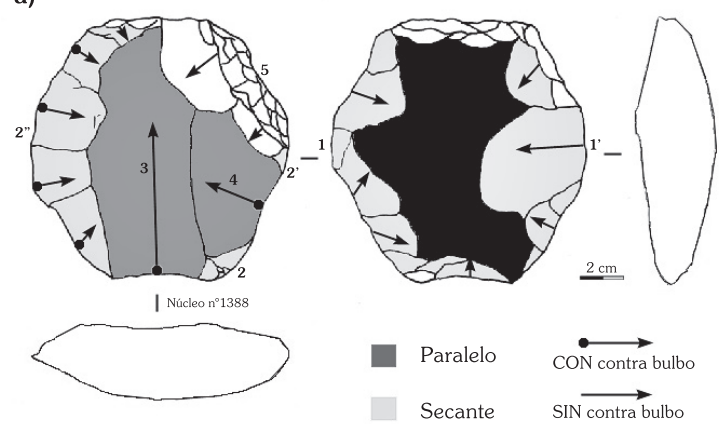

b)

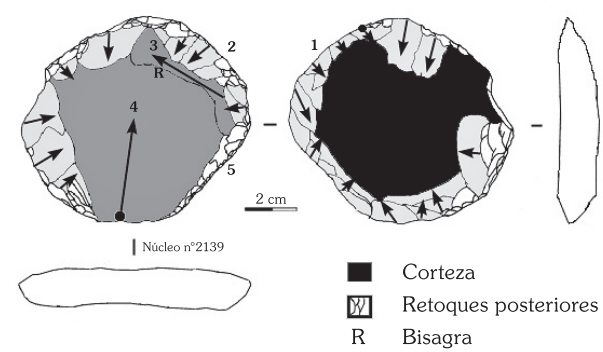

c)

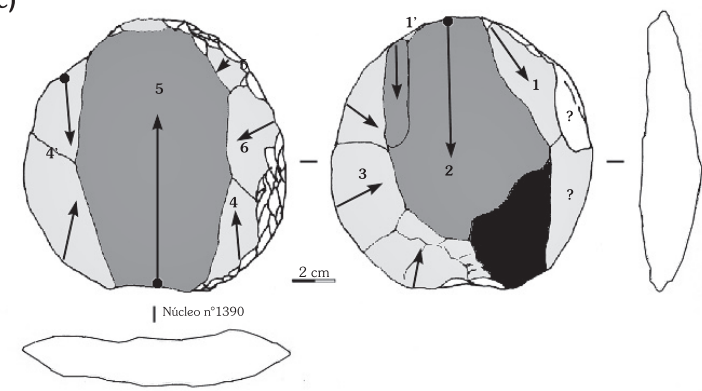

Fig. 6. Esquemas diacríticos: a) y b) núcleos Levallois lineal, c) núcleo Levallois lineal doble.

gendarme). También se registraron planos de percusión lisos $(n=9,16 \%)$, facetados $(n=3,5 \%)$ y otros naturales $(n=6,10 \%)$.

En síntesis, la concepción volumétrica y el sistema de explotación de los núcleos son característicos y coherentes con la configuración y la gestión del desbaste propio del concepto Levallois (Boëda 1984, 1994; Boëda y Pelegrin 1979-80).

\section{Modo de Explotación de superficies Levallois}

En relación a la organización de la producción de lascas predeterminadas en una misma secuencia, se han identificado dos modos presentes en el sitio Cabo San Vicente: el método lineal o a lasca preferencial y el método recurrente (sensu Boëda 1994).
Por el carácter no excluyente de estos modos ${ }^{12}$ de explotación, en la cadena operatoria de una pieza, hemos decidido considerarlos como tipos de explotación y no como métodos distintos. Se considera como modo Lineal todo núcleo que presente un solo negativo de lasca preferencial extendida por secuencia ${ }^{13}$ (Fig. 6). El modo Recurrente se define por la presencia de más de una lasca predeterminada, extendida o semi-extendida, por secuencia (Fig. 7). Además, es posible identificar una o varias series ${ }^{14}$ al interior de cada secuencia de desbaste.

Como modalidad de gestión presente en ambos modos de explotación de la superficie Levallois o combinando ambos modos, se han diferenciado los núcleos que presentan una inversión de la superficie de desbaste (Levallois) y la superficie inferior (plano de percusión) en las diferentes secuencias de desbaste. Esta modalidad corresponde a un manejo especial de las dos superficies convexas y opuestas que son propias de la construcción del volumen Levallois, conformando un volumen más bien simétrico, biconvexo y disminuyendo la jerarquía volumétrica característica ${ }^{15}$. Este manejo se da al costo de ciertas restricciones técnicas necesarias para el éxito de cada extracción, lo que lo vuelve más riesgoso (sensu Boëda y Pelegrin 1979-80). En un sentido formal,

12 Se ha hecho una diferenciación de naturaleza combinada, cualitativa y cuantitativa, entre los términos modo y modalidad, cuyos significados se superponen en buena medida. Utilizamos el término "modo" como identificación de un procedimiento o conjunto de procedimientos para realizar una acción (Diccionario de la Real Academia Española) de forma particular y frecuente, como la explotación de las superficies de desbaste del núcleo. En cambio, el concepto "modalidad" alude a una manera de ser o de manifestarse de algo (Diccionario de la Real Academia Española), una forma particular, y por lo tanto se entiende más bien como una variante formal, una expresión de particularidades morfológicas menos frecuentes. Entonces, las modalidades son consideradas como variantes de menor jerarquía en la subdivisión de los modos de explotación.

13 Una secuencia corresponde a una superficie de desbaste, con una o varias extracciones predeterminadas que cubren la mayoría de esta superficie (más del 70\%).

14 La serie se considera una subdivisión de la secuencia de desbaste Levallois. Se define por la organización y la sucesión de las lascas predeterminadas en la secuencia de desbaste. Las definiciones de secuencia y serie fueron adaptadas de Boëda (1994).

15 La asimetría entre el espesor de la superficie de desbaste (superior) y la cara inferior del núcleo (Boëda y Pelegrin 1979-80). 
Tabla 2. Modos de Explotación.
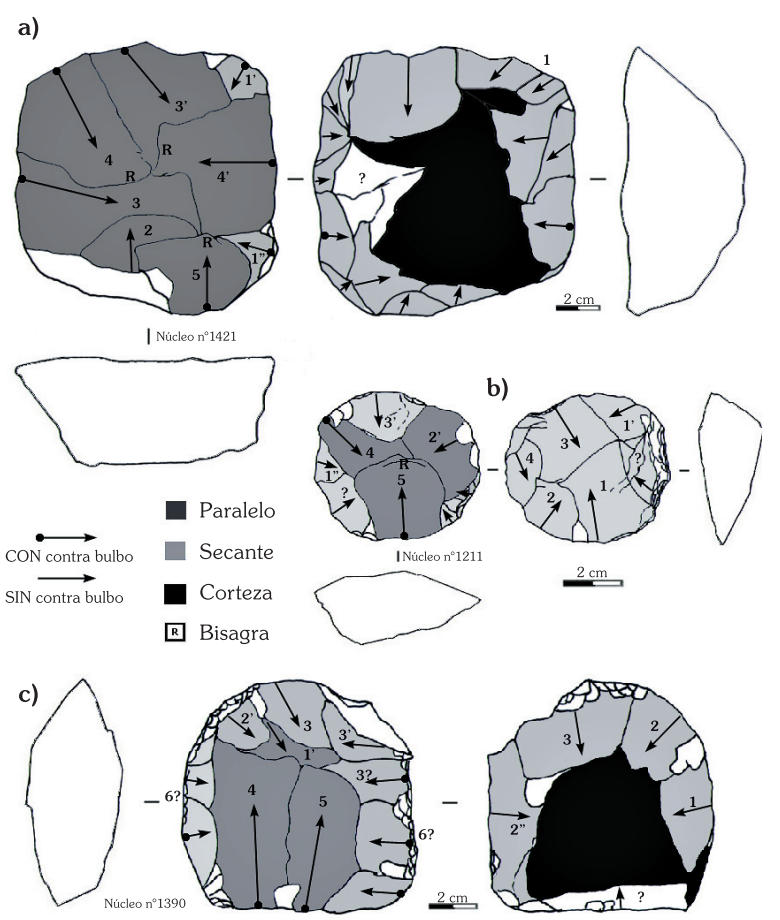

Fig. 7. Esquemas diacríticos de núcleos Levallois recurrentes.

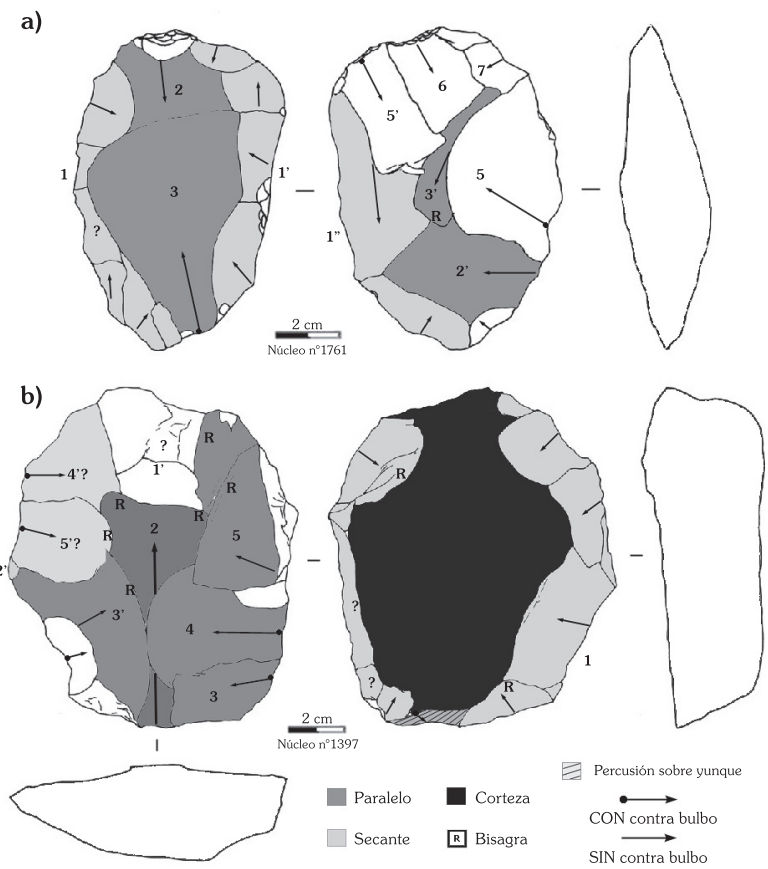

Fig. 8. Esquemas diacríticos: a) núcleo Levallois recurrente doble y b) núcleo Levallois lineal recurrente.

\begin{tabular}{|l|c|}
\hline \multicolumn{1}{|c|}{ Desvaste Levallois } & $\begin{array}{c}\text { Número de } \\
\text { núcleos }\end{array}$ \\
\hline Lineal & 18 \\
\hline Lineal doble & 3 \\
\hline Recurrente & 26 \\
\hline Recurrente doble & 2 \\
\hline Lineal y recurrente doble & 3 \\
\hline Lineal y recurrente & 2 \\
\hline TOTAL & 54 \\
\hline
\end{tabular}

como estos núcleos presentan dos superficies de desbaste Levallois en el momento de su abandono, se les ha llamado "dobles" (Figs. 6c y 8a).

En 2 núcleos se registraron negativos de secuencias de producciones sucesivas, una lineal y otra recurrente, sobre una misma superficie, lo que muestra el carácter no excluyente de estos modos de explotación. Sin embargo, estos casos son pocos, siendo difícil la preservación de las marcas y negativos indicativos debido a la superposición de secuencias de desbaste. Esta cifra representa, entonces, un número mínimo de casos (Fig. 8).

Hemos podido caracterizar tres modalidades de organización de las extracciones de lascas predeterminadas, en una o varias secuencias. Estas modalidades están en directa relación con la cantidad y localización de los planos de percusión. La organización es preferentemente centrípeta, los núcleos de desbaste recurrente han sido en su mayoría configurados en este esquema operacional (13 núcleos recurrentes y 7 de desbaste Levallois lineal, de un total de 22 piezas). En 14 casos la organización es bipolar (10 núcleos recurrentes y 5 lineales). El desbaste unipolar es más frecuente en el método Levallois lineal (10 núcleos lineales, 6 recurrentes, en total 16 piezas). En estos últimos casos de extracción de lascas preferenciales se debe notar que el plano de percusión cambia de posición según las diferentes secuencias de producción en cerca de la mitad de los núcleos lineales estudiados (Fig. 6).

Las lascas buscadas, el producto objetivo de la talla, son visibles a través de los negativos observables sobre el núcleo. En la mayoría de los casos corresponden lascas de forma oval y de dimensiones variables, pero también se han observado dos núcleos en donde se extrajeron láminas sensu stricto, así como tres otras piezas con extracciones de tendencia 


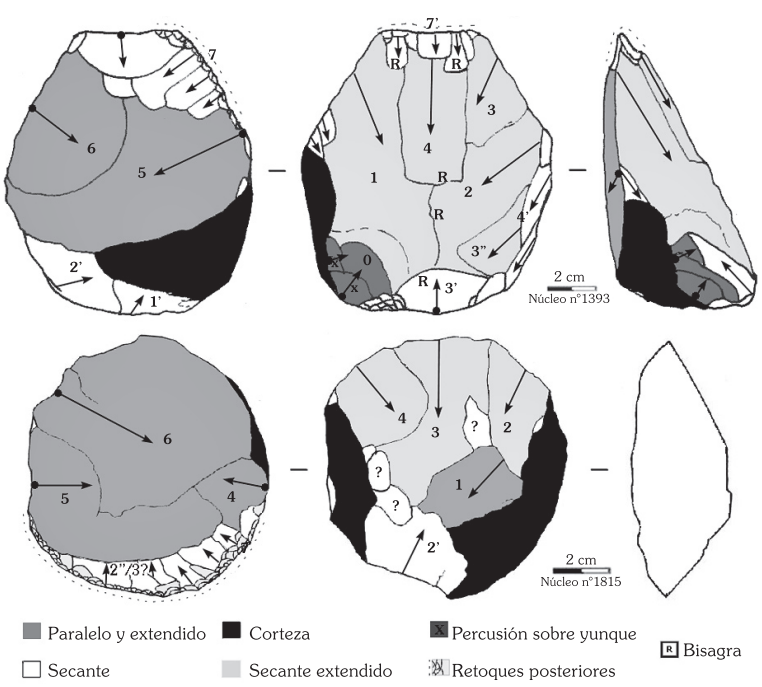

Fig. 9. Esquemas diacríticos de núcleos Levallois asimétrico simplificado.

laminar ${ }^{16}$ (2 núcleos lineales y 3 recurrentes). No se registraron núcleos de desbaste de puntas Levallois o de lascas triangulares.

En las modalidades de gestión del desbaste Levallois se ha distinguido una variante en la construcción del volumen del núcleo: asimétrico en su sección longitudinal al eje morfológico de la pieza, en razón del carácter extendido y convergente de las lascas predeterminantes de la superficie inferior o plano de percusión (Fig. 9). Estas lascas alargadas y secantes son talladas antes que las lascas Levallois de la superficie opuesta (superior). En sí, ellas desplazan el espesor máximo del núcleo hacia el extremo proximal (eje morfológico) el que posee restos de corteza sobre la espalda de la pieza. La modalidad asimétrica puede considerarse igualmente como simplificada en su manejo de las lascas predeterminadas Levallois, debido a la ausencia de preparación de convexidades laterales y distales, siendo éstas reemplazadas por las convexidades naturales de la pieza (corteza). En lo que respecta a las lascas Levallois de estos núcleos, tienen tendencia a ser ligeramente desbordantes, al menos de

16 El criterio "tendencia laminar" incluye lascas alargadas pero que no alcanzan un largo que sea mayor a dos veces el ancho máximo de la extracción. Una diferencia del 10\% es considerada como base. Por ejemplo, una pieza de 100 x 50 mm es considerada una lámina, una lasca de 90 x 50 mm será considerada de tendencia laminar, y una lasca de 89 x $50 \mathrm{~mm}$ fue considerada simplemente como una lasca. un lado. Por lo tanto, junto con la lasca Levallois se extrae generalmente una parte del borde de la superficie de desbaste. Estas extracciones pueden resultar en lascas de dorso natural parcial y/o con talón cortical (plano de percusión natural en el núcleo). Cuatro núcleos de la Colección Cabo San Vicente I presentan esta modalidad: uno muestra un desbaste Levallois más clásico con preparación de convexidad lateral (Fig. 9, inferior), dos otros son núcleos Levallois asimétricos simplificados (Fig. 9, superior), y el cuarto es doble. La inversión de las superficies en esta última pieza crea un esquema diacrítico más complejo pero coherente con los gestos enunciados para esta modalidad. La presencia de un núcleo Levallois asimétrico con clara preparación de convexidad lateral nos indica que la rareza de este criterio de predeterminación del desbaste podría ser resultado de su supresión en el curso de la última secuencia de producción de los núcleos estudiados.

A partir de las observaciones realizadas sobre 3 núcleos Levallois asimétricos simplificados ${ }^{17}$, se nos presenta el cuestionamiento sobre el carácter de las extracciones secantes e invasoras de la superficie inferior - plano de percusión. Dos problemas se presentan: primero, si estas lascas son en sí productos buscados o intencionales y, segundo, si existe alguna restricción o ventaja técnica en esta asimetría en el marco del desbaste Levallois. Con respecto a la primera problemática, no es posible una respuesta en el estado actual del análisis y sin considerar los otros restos líticos del sitio (instrumentos sobre lasca y desechos), pero un elemento adicional al potencial interés de estas lascas es la tendencia alargada, secante y extendida. La necesidad de algunos productos laminares y de tendencia laminar ya se observó en otros 5 núcleos Levallois, por lo que es posible pensar que estas extracciones son productos secundarios pero planificados o predeterminados con anticipación en la configuración del volumen del núcleo.

La existencia de restricciones o de ventajas técnicas que justifiquen esta asimetría en la superficie inferior del núcleo Levallois es por el momento no determinable, pero se sugiere una respuesta probablemente negativa (com. pers. Eric Boëda 2004).

17 En la pieza de desbaste doble no se puede identificar este criterio. 
Sin embargo, en términos teóricos esta configuración de volumen entraña una restricción técnica: la disminución de las posibilidades de localización del plano de percusión de lascas Levallois fuera del sector central distal. Esto debido a la instauración de ángulos muy agudos en la zona distal, que no son adecuados o favorables al plano de percusión necesario para obtener una lasca Levallois, pero que deben funcionar bien para limitar la excesiva propagación y desbordamiento de estas extracciones. Estos argumentos se ven parcialmente reflejados en los dos núcleos estudiados, y faltaría realizar análisis experimentales de manera sistemática para verificar el carácter de estas potenciales restricciones.

En fin, aunque los núcleos asimétricos simplificados sean pocos en el conjunto, nos parece interesante considerarlos como una modalidad susceptible de ponerse en evidencia en cuanto a posibles preguntas sobre las elecciones, restricciones y manejo diferencial de este desbaste. Como última problemática, es interesante plantearse si esta modalidad era intercambiable con otros modos de explotación del desbaste Levallois, en una misma cadena operatoria, o si corresponde a un manejo del volumen escogido desde el comienzo y relativamente fijo. Esto incluiría una tercera pregunta tecnológica a las dos anteriores, que permanecerán sin resolver por ahora.

En síntesis, dos modos de explotación y cinco modalidades han sido identificados y definidos, ya sea sobre la base de la organización de la explotación o producción de la superficie de desbaste, la variabilidad en la gestión del volumen del núcleo (doble o asimétrico), o por la forma de manejo de la superficie de desbaste (centrípeta, bipolar, unipolar). Las opciones de combinación son múltiples y las modalidades pueden resultar en una gran cantidad de clases de desbaste, según se observó en el conjunto. Esta variabilidad no afecta la coherencia del concepto Levallois, según los criterios y definición señalados anteriormente.

\section{Inicialización y Abandono}

A partir de 4 núcleos fallidos ${ }^{18}$, se ha podido observar en parte los procedimientos de selección de bloques o soportes de núcleo, y en otra parte,

18 Uno por un accidente de talla y los otros tres por problemas en la materia prima. la puesta en forma inicial del volumen Levallois. Registran dos modos de inicialización (representados cada uno con 2 piezas) en donde se nota un grado de selección del guijarro natural con formas apropiadas: en los primeros casos se utilizaron lascas corticales espesas, y en el segundo, se seleccionaron guijarros que presentan volumen previamente compatibles con este método (dos superficies asimétricas jerarquizadas y con convexidades naturales). Una superficie del bloque se formaliza como plano de percusión y la otra se utiliza como superficie de desbaste. Los primeros productos de fractura paralela pueden portar restos de corteza sobre su cara dorsal. Además, en otros 4 núcleos hemos detectado el uso de la técnica de percusión sobre yunque. Esta técnica pudo ser utilizada como medio de obtención de una masa central sobre la cual confeccionar el núcleo, o como vía de apertura de planos de percusión lisos, y/o eventualmente podría estar destinada al descortezamiento y adelgazamiento parcial de los nódulos de guijarro, antes de la puesta en forma del volumen Levallois.

Todas las observaciones señaladas sobre el método Levallois deben considerarse en función del estado en el cual fueron abandonados los núcleos. En las piezas estudiadas de Cabo San Vicente I, el abandono puede explicarse por los siguientes criterios o combinaciones de éstos:

- En relación a un volumen próximo al agotamiento (en este caso el criterio más pertinente parece ser el espesor reducido de algunos núcleos, con respecto a la dimensión de la superficie de desbaste).

- Por la acumulación de accidentes de talla (bisagras y fracturas que se presentan en diferentes grados y cantidades en todas las piezas).

- Debido al estado abrupto de los ángulos de la superficie inferior (plano de percusión cercano o superior a $90^{\circ}$ ).

- Y, por problemas en las materias primas, que a medida que avanza la talla limitan el núcleo a las zonas menos aptas del bloque (frecuentes líneas de clivaje e impurezas) $)^{19}$.

19 En el desbaste Levallois de Cabo San Vicente, un 81\% de las materias primas utilizadas son buenas a regulares $(14 \%$ muy buenas a buenas, $5 \%$ regulares a mediocres). Algunas rocas pueden ser homogéneas, pero otras son irregulares y presentan sobre un mismo bloque variaciones de bueno a mediocre, con diferentes etapas intermedias (por ejemplo la materia prima $\mathrm{n}^{\circ} 5$ ). 
Tabla 3. Distribución de corteza sobre la superficie inferior de los núcleos Levallois.

\begin{tabular}{|l|c|c|}
\hline \multicolumn{1}{|c|}{ Corteza } & Frecuencia & Porcentaje (\%) \\
\hline entre 0 y $25 \%$ & 25 & 43 \\
\hline entre 25 y $50 \%$ & 14 & 24 \\
\hline entre 50 y $75 \%$ & 12 & 21 \\
\hline entre 75 y $100 \%$ & 7 & 12 \\
\hline TOTAL & 58 & 100 \\
\hline
\end{tabular}

Sin embargo, nos parece difícil de sostener, excepto en algunos casos de núcleos muy delgados, que el "volumen" explotable esté totalmente agotado.

Los porcentajes de corteza observados en la cara inferior o plano de percusión de los núcleos pueden considerarse una variable indicativa del estado de abandono. Generalmente, cada vez que el volumen Levallois es renovado o reavivado para una nueva serie de producción, la superficie de desbaste es arreglada, al igual que el plano de percusión. La reducción del volumen del núcleo y el resto de corteza de la superficie inferior es progresivo en el proceso de explotación. Podemos prever que el porcentaje de corteza será en parte función de la intensidad de explotación y/o indicador del grado de manutención y reavivado del núcleo (Tabla 3 ). La presencia de corteza sobre los núcleos es un aspecto complementario a la observación de las secuencias de extracciones predeterminadas, es decir, la producción del núcleo. En la mayoría de las piezas se registró la presencia de dos o más secuencias de lascas predeterminadas - Levallois - con una o varias series sobre la misma superficie de desbaste. Así, aunque hay una gran cantidad de núcleos abandonados luego de una explotación de mediana intensidad, se observa que éstos son abandonados en todos los estados posibles, aspecto que se explica en parte por los varios criterios señalados en el párrafo precedente.

\section{Núcleos Retomados}

Varias piezas del método Levallois de la colección San Vicente nos permitieron detectar y diferenciar tres tipos de casos de retomado o reclamo de núcleos, concepto entendido en el sentido general de una acción de retomar un procedimiento luego de una interrupción de tiempo variable, días, años, centurias... Este concepto concuerda con el de reclamación de Schiffer (1987).
Un primer tipo de retomado se materializa sobre el material lítico por la identificación de pátinas diferenciales muy marcadas en su superficie $e^{20}$. Incluye 6 núcleos (10\% del total del método Levallois), entre los cuales 4 fueron retomados en el cuadro del concepto Levallois y otros 2 en un desbaste no-Levallois.

El segundo tipo de reclamación se registró en 4 núcleos, a partir del análisis de los esquemas diacríticos que indicaban un retomado marcado por cambios en el método de desbaste. Considerando los dos casos mencionados anteriormente, serían en total 6 los núcleos retomados siguiendo un desbaste no-Levallois: 3 retomados por un desbaste discoideo alterno, 2 siguiendo un desbaste secante convergente sobre una superficie y un no-Levallois indeterminado.

Los últimos casos incluyen el retomado del núcleo como instrumento, los que se identifican a partir de la presencia de un borde o varios con retoque continuo y delimitando un borde regular. Esta acción se presenta en 24 núcleos Levallois (41\%), a pesar de haber un número importante de indeterminados $(22 \%)^{21}$. Luego de la interrupción del desbaste, entonces, se registra el paso de una cadena de desbaste a una de utilización.

Los tres tipos de retomado no son excluyentes y no presentan un orden definido, como lo ilustra el caso del núcleo no 1391 desbastado inicialmente como núcleo indeterminado, luego retomado como instrumento, posteriormente reciclado bajo un sistema de desbaste Levallois y finalmente retocado como instrumento y abandonado. También destacamos el núcleo $n^{\circ} 2118$ que comienza como núcleo Levallois, luego es retomado como instrumento (formación

20 Esta cifra debe considerarse un mínimo de casos, ya que 21 núcleos (36\%) registran pátinas indeterminadas. Es decir, que hay un número importante de piezas patinadas en las que no se puede determinar si la superficie más fresca del núcleo es el resultado de un retomado antrópico o las pátinas han sido originadas por procesos post-depositacionales asociadas a un enterramiento parcial de la pieza. En el último caso, las huellas diagnósticas que hemos utilizado en nuestro análisis para diferenciar las pátinas naturales de aquéllas de origen humano son: la identificación de una pátina concordante con las líneas topográficas de la pieza y/o pátinas que "cortan" o dividen un mismo negativo o varios a la vez. Además, debemos notar, que en varios núcleos se observaron distintos grados de pátina.

21 Los indeterminados incluyen piezas de retoque dudoso, que podrían ser producto del uso de los bordes o huellas generadas por procesos post-depositacionales. 


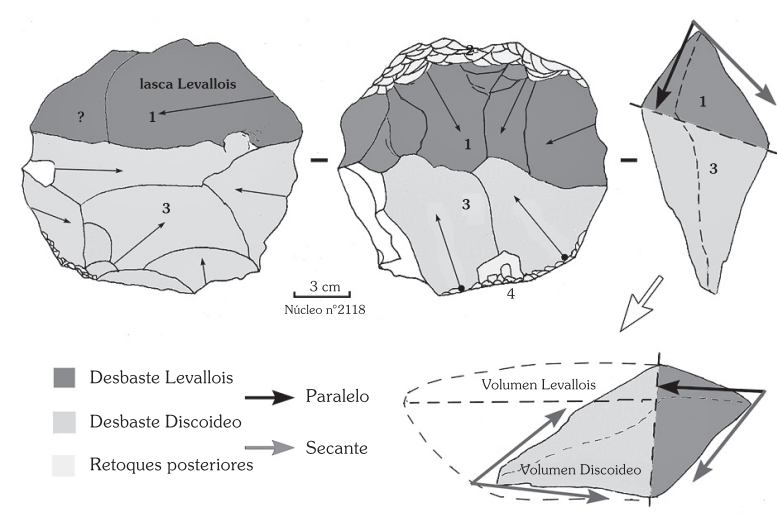

Fig. 10. Ejemplo de núcleo Levallois retomado: 1) desbaste según el método Levallois, 2) retoque del borde, 3) retomado según los criterios del desbaste discoideo y 4) retoque del borde, y abandono.

de pátina), y posteriormente retomado siguiendo un desbaste discoideo y finalmente retocado como instrumento antes de ser abandonado (Fig. 10).

\section{MÉTODO UNIPOLAR SECANTE SOBRE LASCA ESPESA}

El método unipolar secante sobre lasca espesa está registrado a través de 18 núcleos. Estas piezas se asemejan a cepillos, y algunas piezas parecen formatizadas y posiblemente utilizadas como instrumentos de este tipo. No obstante, presentan negativos de extracciones compatibles con soportes de raspadores clasificados en la categoría de instrumentos sobre lascas retocadas en la colección Cabo San Vicente I. Los criterios considerados para establecer esta compatibilidad entre raspadores y núcleos son: la dimensión, la morfología regular de las lascas $^{22}$, los ángulos de caza (secantes), la presencia de talón liso ${ }^{23}$, y la organización de los negativos de la cara superior de los raspadores (unipolar). Estos pseudo-cepillos fueron estudiados como núcleos, evaluándose a posteriori los criterios tecnológicos que podrían indicar el retomado de estos núcleos como instrumentos. Pero, la confirmación de este

22 El criterio de regularidad de las lascas y la presencia exclusiva de negativos unipolares (dorso) en la misma dirección tecnológica que la lasca permite diferenciar entre estos productos y las lascas de desbaste discoideo.

23 El ángulo secante y el talón serían los criterios que permitirían diferenciar estos productos de las extracciones predeterminantes semi-extendidas del método Levallois recurrente.
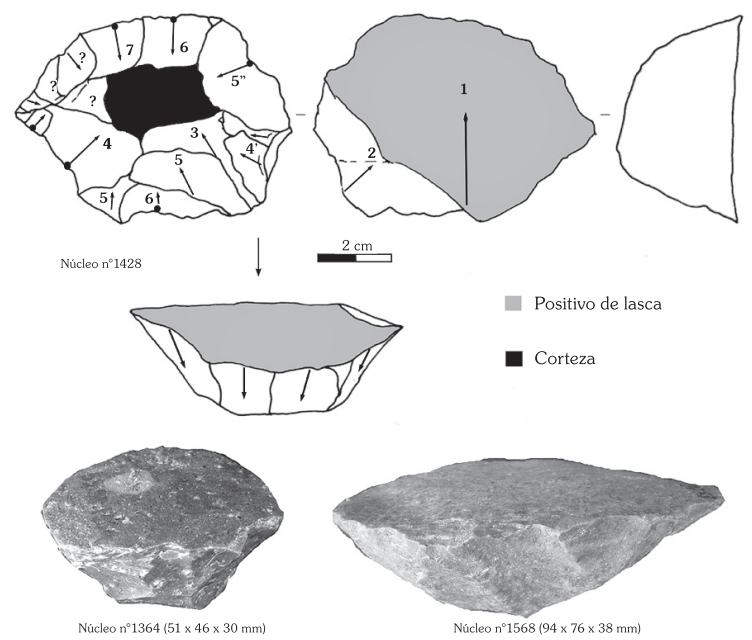

Fig. 11. Esquema diacrítico y fotografías de núcleos de desbaste unipolar secante sobre lasca gruesa.

retomado y su utilización como cepillos sólo podrán confirmarse a través de estudios de traceología.

Los criterios de gestión y procedimientos técnicos de este método de desbaste incluyen (Fig. 11):

1. El establecimiento de un plano de percusión único, ligeramente convexo, formado por el positivo de una lasca espesa que constituye la masa central del núcleo. Sobre 18 núcleos, 16 presentaban indicios claros de este positivo de lasca espesa, y en 2 piezas no era posible discriminar este rasgo. Se observó en 6 núcleos una formatización posterior del plano de percusión, consistente en 1 a 3 extracciones paralelas al eje tecnológico de la lasca - soporte del núcleo. Estos fragmentos de negativos de lasca, anteriores a las extracciones de las últimas lascas secantes - los productos del desbaste - se explican como parte de antiguos arreglos del plano de percusión.

2. El volumen del núcleo está definido por dos superficies jerarquizadas en su rol y en relación a su volumen: un plano de percusión de tendencia plana y una superficie de desbaste de tendencia convexa (o también de sección sub-trapezoidal a sub-triangular). El plano de intersección imaginario de estas dos superficies es aproximadamente concordante con el plano de percusión.

3. Los productos de desbaste son extracciones de ángulo secante con relación al único plano de percusión existente (ángulos preferentemente entre $60^{\circ}$ y $80^{\circ}$ ). Los núcleos, entonces, son unipolares. El plano de fractura de las lascas es semi-extendido y 
tiene una orientación centrípeta o convergente hacia la zona central del núcleo. Estas dos características dan a la superficie de desbaste de cada pieza una silueta de tendencia ovalar, sub-circular o sub-cuadrada, en que los largos y anchos máximos son de dimensiones muy cercanas.

4. Las extracciones secantes - la producción - son organizadas de manera contigua y continua, pero sin un orden aparente. Las distribuciones varían según la pieza, y se obtienen por percusión directa dura. Estos productos se extienden sobre toda la periferia de la superficie de desbaste en casi la mitad de los núcleos estudiados (44\%), y en las otras piezas se extienden por 3/4 o la mitad de los bordes. En algunos casos es posible distinguir dos secuencias superpuestas de estas extracciones.

5. El control o predeterminación del largo de las lascas producidas está dado por el ángulo de caza secante en combinación con el espesor del núcleo y su sección casi convexa.

Ocho núcleos (50\%) presentan menos de $25 \%$ de corteza sobre la cara de desbaste, 3 registran entre 25\% y 50\%, y 2 presentan cerca del 75\% (4 piezas indeterminadas ${ }^{24}$ ). En todos los casos la corteza se presenta en la zona central de la superficie, e indica que probablemente las lascas utilizadas como soporte eran corticales o primarias. La corteza ha sido parcialmente suprimida por las extracciones secantes y semi-extendidas. De 6 núcleos que presentan aún el talón de esta lasca espesa de soporte, dos son naturales y 4 lisos. Además, 3 poseen marcas características que indican que estas lascas espesas fueron desbastadas por percusión sobre yunque.

Las características de las lascas de la producción serán discutidas más adelante, en comparación con los otros métodos de desbaste. Quisiéramos notar solamente, por ahora, la presencia de un núcleo con extracciones de tendencia laminar (núcleo $n^{\circ}$ 1568).

Con relación a la causa de abandono de estos núcleos, es difícil estimar si esto se debe a su agotamiento. En efecto, es frecuente que la cadena operatoria de estos núcleos sea modificada por su introducción a la cadena de utilización (cepillos).

24 Estos casos de porcentaje indeterminado de corteza tienen pátinas diferenciales que no permiten distinguir claramente entre pátina y corteza.
En los núcleos de desbaste unipolar sobre lasca espesa, ciertos criterios tecnológicos indican el retomado de piezas como instrumentos. En primer lugar, destacamos que 6 núcleos presentan bordes retocados, formando bordes potencialmente utilizables como cepillos y un caso más regular evoca un raspador espeso. La identificación de piezas retocadas incluye núcleos de bordes claramente retocados de manera continua y de frente regular, notándose 2 casos indeterminados. También se observaron otras huellas en los bordes de la intersección del plano de percusión y la superficie de desbaste. Estas marcas se ligan posiblemente al retomado de núcleos como percutores $\mathrm{u}$ otras funciones indeterminadas: 16 piezas tienen los bordes esquirlados, 11 muestran huellas de trituramiento (abujardados) y 4 tienen sus bordes romos, abradidos.

En fin, 10 núcleos presentan pátinas diferenciales de origen indeterminado, relacionándose tanto con posibles retomados antrópicos o también podrían corresponder a pátinas originadas por condiciones post-depositacionales.

\section{MÉTODO EN TAJADAS SOBRE YUNQUE}

Según se explicó anteriormente en la metodología, el desbaste bipolar o sobre yunque se considera como una técnica de aplicación de la fuerza en el cuadro de la talla lítica. Esta técnica puede participar de diversas maneras en las cadenas operatorias, como procedimiento de fractura de un guijarro, como sistema de adelgazamiento de la corteza del bloque, como técnica principal de un método, etc.

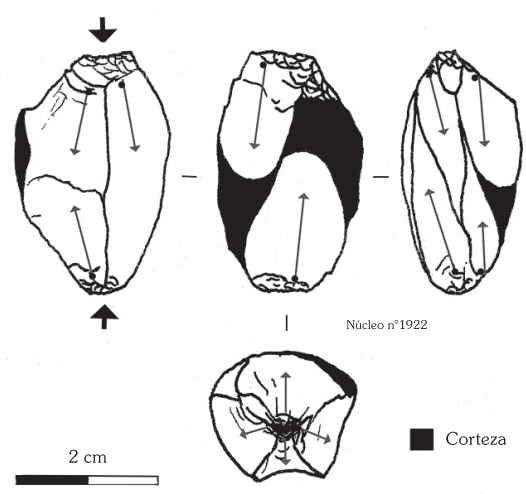

Fig. 12. Núcleo de jaspe desbastado por percusión dura sobre yunque del tipo split. 


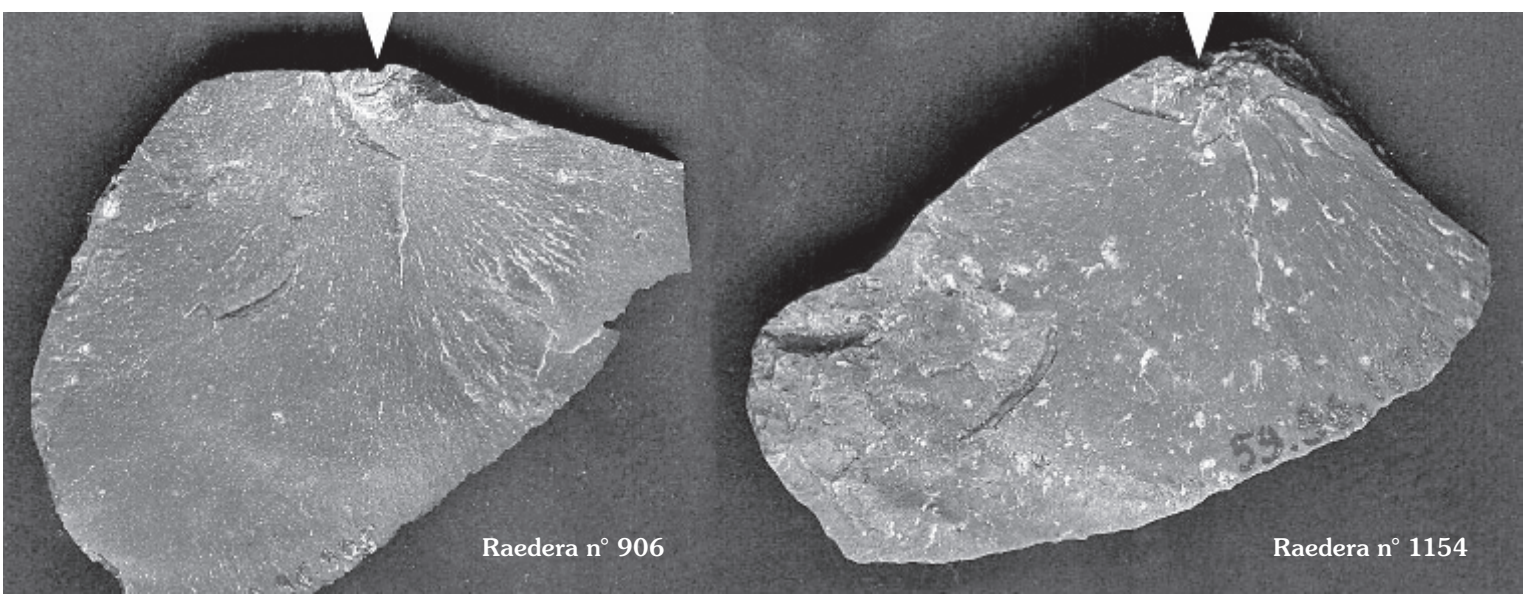

Fig. 13. Raederas sobre lascas de dorso natural, obtenidas por percusión dura sobre yunque y que muestran los criterios utilizados para la identificación de esta técnica de aplicación de la fuerza de extracción.

En los núcleos de la Colección Cabo San Vicente I se ha registrado dos modos de utilización de esta técnica. Una corresponde a un procedimiento de fracturación poco controlado (sensu Pelegrin) que se conoce como split o piezas esquirladas.

\section{Split}

Se registraron 3 núcleos de este tipo en el sitio. El procedimiento se utilizó para fracturar 2 pequeños núcleos de jaspe (Fig. 12) y el tercero es una pieza más grande. Las huellas características que identifican este procedimiento es la presencia de dos bordes opuestos con esquirlamientos o astillamientos (Brézillon 1983; Leroi-Gourhan 1988) y su asociación con extracciones que pueden ser unipolares o bipolares. La morfología de estos núcleos es poliédrica (una superficie de desbaste o varias, que parten de polos opuestos), y generalmente de sección transversal biconvexa y longitudinal al eje tecnológico de la pieza. Los núcleos son producto de la fuerza bipolar generada por el percutor y el yunque de manera simultánea en la percusión. Los negativos de extracciones no presentan contra-bulbo o éste se presente difuso. Estos núcleos son escasos y serán excluidos de las discusiones posteriores.

\section{Desbaste en tajadas sobre yunque}

El segundo método que utiliza la técnica de percusión sobre yunque es un método de desbaste llamado "en tajadas sobre yunque". Está representado por 11 núcleos y 18 raederas que se identificaron en el análisis preliminar del material de la terraza alta y que corresponden a soportes producidos por este método de talla. Las huellas que permiten definir esta técnica de percusión sobre núcleos y sus productos $\operatorname{son}^{25}$ (Fig. 13):

- La apariencia muy plana de la superficie de desbaste, debido a la ausencia de contra-bulbo en los núcleos o de bulbo en la cara ventral de las lascas. Este carácter está presente en todas las piezas, y explica por qué es difícil diferenciar un positivo de un negativo y viceversa. Algunas piezas presentan raras ondas sobre la porción distal de la extracción.

- El punto de impacto del percutor y el punto de apoyo en el yunque, si están presentes, muestran un aspecto triturado y aplastado, que puede estar rodeado de esquirlas y astillamiento en una o las dos superficies adyacentes al punto de percusión. Este criterio está presente sobre un 78\% de las raederas (3 ausentes y 1 indeterminado), y un $72 \%$ de los núcleos (3 casos indeterminados).

- El ángulo de caza en el núcleo puede ser superior a $90^{\circ}$, carácter que es muy diagnóstico si está presente (com. pers. J. Pelegrin 2004). Pero, en general los núcleos estudiados muestran un predominio de ángulos entre $80^{\circ}$ y $90^{\circ 26}$. Lo mismo

25 Observaciones realizadas sobre la colección de referencia experimental de J. Pelegrin y en relación al estudio del material arqueológico de la Colección Cabo San Vicente I.

26 Cuatro núcleos presentan ángulos entre $80^{\circ}$ y $90^{\circ}$ o más, una pieza tiene ángulos entre $60-70^{\circ}$, y hay 6 casos indeterminados. 
sucede para las raederas: 10 presentan ángulos iguales o superiores a $90^{\circ 27}$.

- Algunas piezas presentan un accidente característico: una extracción simultánea a la fracturación de la lasca-producto. Se ubica sobre su cara dorsal, teniendo el mismo punto de impacto que el positivo de la lasca.

- En teoría, también deberían observarse ondas de direcciones opuestas a partir de las dos extremidades de las extracciones, pero este criterio no está representado en la colección de Cabo San Vicente.

En la colección estudiada, la gestión del método de tajadas sobre yunque comienza sin ninguna preparación del guijarro seleccionado, aspecto puesto en evidencia por la presencia de dos lascas (raederas) corticales. Las extracciones se organizan alternativamente de manera centrípeta (lo más frecuente), bipolar o unipolar (aspecto observado en el negativo de los núcleos, y en las caras superiores de las raederas sobre lasca). Las primeras lascas pueden ser corticales, luego presentar distintos porcentajes de corteza sobre su cara dorsal; la mayoría de las raederas no tienen corteza. El desbaste se organiza de manera progresiva a partir de las dos extremidades del bloque (2 núcleos) o de uno solo. Los núcleos pueden presentar una superficie cortical o ninguna, tienen una o dos superficies de desbaste sub-paralelas, y poseen algunas zonas corticales en el dorso. Lo mismo sucede para el dorso de las lascas, pero con una diferencia previsible en las proporciones: algunas raederas tienen una buena proporción de corteza $\left(33 \%{ }^{28}\right.$ ) y la mayoría (67\%) tiene muy poco, o incluso nada en absoluto (Fig. 14).

El gesto de percusión causa la extracción de solamente una parte de la superficie de desbaste. Esto crea productos de sección longitudinal triangular, cuyo espesor máximo se sitúa cerca del talón y presenta una disminución gradual en dirección del sector distal de la lasca, en cuña ${ }^{29}$. Frecuentemente una parte de la espalda o dorso y/o del talón de los

27 Entre $90^{\circ}$ y $130^{\circ}$. También se registró una raedera con un ángulo de $65^{\circ}$, otra de $80^{\circ}$ y las 6 restantes no son determinables.

283 raederas con $75 \%$ a $100 \%$ de corteza en la cara superior, 1 pieza con cerca de $50 \%$, y 2 con $25-50 \%$ de corteza.

29 En teoría, si esta morfología no fuera intencional, las lascas o productos de este método podrían tener un espesor constante - por lo tanto, representando tajadas o tramos de sección regular. productos es cortical. Un 25\% de los bordes de las lascas-raederas no es legible debido al retoque ${ }^{30}$. Entre ellos 4 piezas presentan 50\% al 60\% de dorso natural, una mayoría de 12 raederas se sitúa entre $25 \%$ y $50 \%$ de corteza sobre la espalda y/o el talón, un caso presenta un 15\% y un resto indeterminado. Entonces, siempre resta una porción de dorso cortical, y el talón, cuando está presente, es natural. Estas dos características (sección longitudinal en cuña y dorso en parte cortical) pueden considerarse como criterios en parte diagnósticos para identificar los productos de este método, junto con los criterios de definición de la técnica de aplicación de fuerza (percusión sobre yunque) - Fig. 14.

Estos núcleos, en su estado terminal, presentan una forma muy agotada que se asemeja más a un desecho que a un núcleo. En este sentido, los criterios para identificar los núcleos son menos evidentes en el conjunto porque la morfología de los núcleos es muy variable.

Por último, una mención separada debe hacerse sobre las materias primas utilizadas. Para los núcleos se observó un predominio de rocas de estructura similar al esquisto y propicios a esta técnica ( 9 piezas, $82 \%$ de los núcleos). No obstante otras materias primas de fractura concoidal (15 raederas, 83\%) también fueron utilizadas. El método descrito no se limita, pues, a rocas especialmente adecuadas: aunque los núcleos-desechos analizados estén esencialmente hechos sobre rocas de estructura esquistosa o del tipo laja, estaría faltando en la colección una gran parte de los núcleos de materias primas a fractura concoidal que están presentes en forma de raederas (productos del método en tajadas sobre yunque) ${ }^{31}$.

\section{MÉTODO DISCOIDEO}

Sobre 4 núcleos, se observó el desarrollo de un método de desbaste conocido como discoideo, coincidiendo con las características descritas por Boëda (1994). Además se deben considerar 3

30 Todas las raederas presentan un retoque marginal simple, generalmente transversal, y con diversos grados de reavivado. Por lo tanto, parte del borde de la lasca base ha sido extraído por el retoque.

31 La recolección efectiva de los núcleos-desechos sobre roca similar al esquisto en estructura, nos permite eliminar un posible sesgo en la recolección de estos artefactos muy amorfos y poco formalizados. 
1

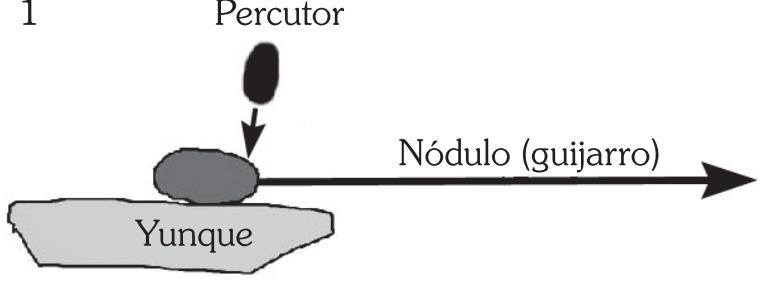

2
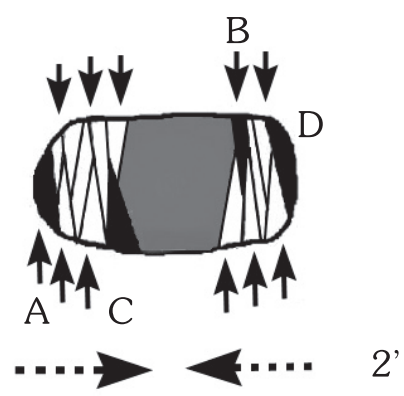

direcciones del desbaste
3

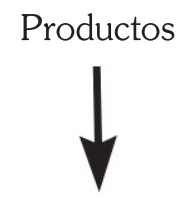

A

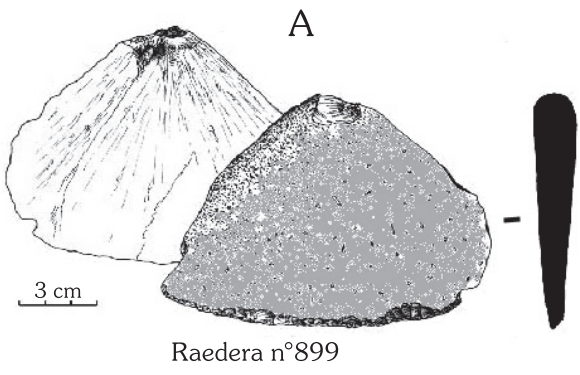

$\mathrm{B}$

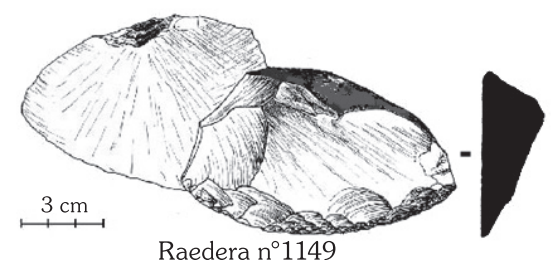

***

Núcleos

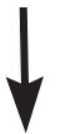

Fig. 14. Reconstrucción que ilustra parte de la cadena operatoria del método de desbaste en tajadas sobre yunque.

núcleos Levallois retomados en su última etapa de desbaste como núcleos discoideos. El método discoideo se organiza a partir de dos superficies más o menos convexas y secantes, pero el criterio que lo diferencia de los núcleos Levallois es el carácter no jerarquizado de éstas, y el papel alternante de la superficie de desbaste y el plano de percusión (6 núcleos). Mientras que se registra un determinado grado de anticipación en las formas de los productos, no se observa una distinción funcional entre extracciones predeterminantes y predeterminadas. Además las lascas son secantes con relación al plano de intersección de las dos superficies, aspecto que difiere notablemente con el método Levallois. Estas extracciones secantes son semi-extendidas a invasoras (no es frecuente que las lascas superen 


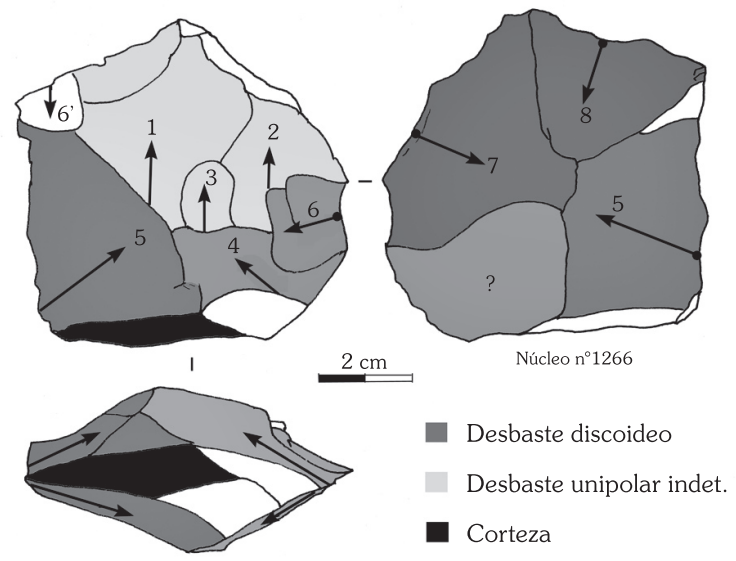

Fig. 15. Esquema diacrítico de núcleo unipolar indeterminado retomado bajo el esquema del método Discoideo.

la mitad de la longitud máxima de la pieza). Por último, la técnica utilizada es la percusión directa con percutor duro (Fig. 15).

Nos pareció difícil evaluar el estado de abandono de estos núcleos, excepto en el caso de un pequeño núcleo de jaspe donde la materia prima era defectuosa. Los otros presentan volúmenes aún explotables, a condición de que las exigencias morfo-métricas sean modestas.

Tres núcleos Levallois y 2 otros núcleos se retomaron bajo un sistema discoideo. Entre estos últimos, uno presenta negativos unipolares sobre una superficie de desbaste previa al método discoideo; en el otro se ha precedido un desbaste indeterminado puesto en evidencia por fragmentos de negativos que presentaban una pátina diferencial a la de las retomadas en el marco del desbaste discoideo.

\section{PRODUCTOS Y MÉTODOS}

En síntesis, el desbaste a Cabo San Vicente está representado por cuatro métodos de producción de soportes. El método Levallois, el desbaste unipolar secante y el desbaste en tajadas sobre yunque se estructuran de manera bastante rígida en su esquema operatorio y su mantenimiento o manejo del volumen del núcleo. Las restricciones materiales son homogéneas para todos los sistemas de desbaste (materias primas locales), y no hay relación entre materias primas particulares y un método. Así, el carácter estructurado de los esquemas operatorios podría ser la expresión de un fenómeno cultural: el aprendizaje sistemático y el desarrollo de habilidades. Citemos a este respecto las observaciones de Anne Chapman sobre el alto grado de instrucción necesaria entre los Selk'nam para adiestrarse en las tareas de cazador y también las de tallador, desarrolladas solamente por los hombres (Bridges 2000 [1948]; Chapman 1977).

El desbaste discoideo y los procedimientos de split parecen más circunstanciales. Esto podría vincularse con el reducido número de casos, y con su carácter de desbaste "secundario" en las piezas retomadas (caso de los núcleos discoideos), y también con su esquema operatorio poco elaborado (Inizan et al. 1995).

¿Cuáles son los productos obtenidos a partir de estos distintos métodos de desbaste? Los soportes buscados no son especialmente largos; los casos de extracciones laminares son muy anecdóticos y raros, tanto en el método Levallois como para un caso del núcleo unipolar secante sobre lasca espesa.

Con la intención de comparar los productos potenciales de los métodos de desbaste, medimos la longitud y el ancho de los negativos sobre los núcleos, y en el caso del método en tajadas sobre yunque, se consideraron los productos mismos (las raederas). Sin embargo, debemos ser conscientes de que las medidas son una aproximación parcialmente sesgada, porque se refieren a las últimas lascas posibles de un núcleo ${ }^{32}$ y debido a la alteración generada por el retoque de los bordes, y el reavivado en el caso de las raederas. En el gráfico (Fig. 16), se observa una síntesis de este análisis; se eligió la medida máxima del producto, longitud o ancho según el caso ${ }^{33}$.

Los productos obtenidos varían en dimensión, pero se observan también superposiciones métricas entre los distintos métodos de desbaste. La producción de lascas más grandes, o en su longitud (más frecuente en el método Levallois lineal) o en su

32 En casi todas las piezas la medida corresponde a la última extracción considerada como un producto de primera selección, sino a lascas anteriores pero que conserven su punto de impacto y que se encuentren casi enteras. Las únicas excepciones son las medidas de los núcleos unipolares secantes para los cuales se calculó un promedio de las medidas de varios negativos de lascas (3 a 5 lascas por núcleo).

33 Estas medidas se realizaron a partir de 18 productos de desbaste en tajadas (raederas) y sobre 63 núcleos de otros métodos. Dos medidas se tomaron para los 3 núcleos Levallois retomados como discoideos. 
ancho (frecuente para las raederas de desbaste en tajadas sobre yunque), son obtenidas principalmente por el método Levallois lineal y el desbaste en tajadas sobre yunque (máximo entre 150 y 100 mm). También se observa una superposición entre los dos modos de explotación de la superficie Levallois y el método discoideo (entre 100 y $50 \mathrm{~mm}$ ). Finalmente, los núcleos unipolar secante proporcionan extracciones en general bastante pequeñas y que presentan un grado de superposición con núcleos Levallois recurrentes y discoideos.

Los productos Levallois muestran una notable variedad métrica. Al observar el conjunto nos pareció evidente que, independientemente de la dimensión de los núcleos, el criterio dominante en la opción de modo de explotación y modalidad utilizada, es la búsqueda de un producto morfo-métricamente específico. Este producto se prevé necesariamente con anticipación, al menos en cada secuencia de producción. Pues un núcleo Levallois lineal de dimensión media a pequeña puede producir el mismo tipo de lasca que un núcleo Levallois recurrente, 4 veces mayor en tamaño. Al contrario, los núcleos Levallois lineal y recurrente de dimensiones similares proporcionan productos métricamente muy diferentes. Por último, se debe tener en cuenta que hay una diferencia cuantitativa en la producción de los núcleos Levallois lineal y recurrente. Luego, en algunas escasas piezas, la morfología y las dimensiones del bloque elegido limitan las posibilidades.

Los productos buscados en cada método presentan dimensiones variadas. ¿Su morfometría se vincula con la morfología de las lascas o con la

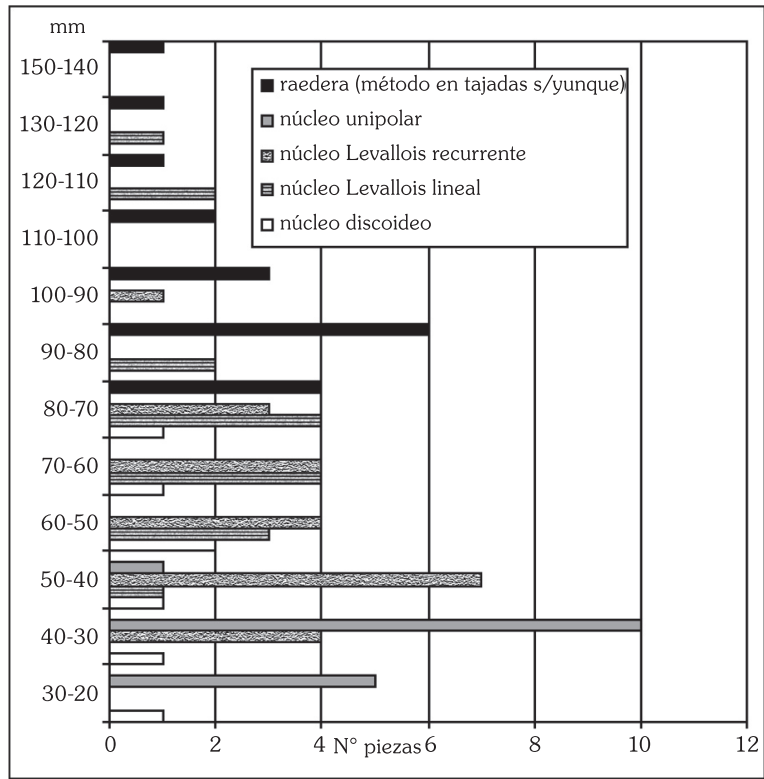

Fig. 16. Frecuencia de dimensión máxima de productos de desbaste según método.

recurrencia de la explotación? En la Tabla 4 se intentó hacer una síntesis general de las características de la producción en cada método. Como ya lo observamos hay superposiciones morfométricas en las características de los productos de cada método y también en la representación de su recurrencia. Sin embargo, nunca hay una coincidencia total de los parámetros analizados para caracterizar la producción de cada método de desbaste. La producción de cada método es, entonces, relativamente diferente. Además, al suponer la ausencia de dificultades materiales

Tabla 4. Síntesis de la producción de los métodos de desbaste.

\begin{tabular}{|c|c|c|c|c|c|}
\hline MÉTODO & $\begin{array}{l}\text { MORFOLOGÍA } \\
\text { PRODUCTOS }\end{array}$ & $\begin{array}{c}\text { SECCIÓN } \\
\text { PRODUCTOS }\end{array}$ & $\begin{array}{l}\text { DIMENSIÓN } \\
\text { PRODUCTOS }\end{array}$ & $\begin{array}{c}\text { MODOS/ } \\
\text { MODALIDADES }\end{array}$ & $\begin{array}{l}\text { RECURRENCIA DE LA } \\
\text { PRODUCCIÓN }\end{array}$ \\
\hline Levallois & $\begin{array}{l}\text { > ovoidal, regular (en } \\
\text { todos los casos) }\end{array}$ & $\begin{array}{l}\text { regularmente } \\
\text { fino }\end{array}$ & $\begin{array}{l}\text { grande, } \\
\text { mediana y } \\
\text { pequeña }\end{array}$ & $\begin{array}{l}2 \text { modos, } \\
5 \text { modalidades }\end{array}$ & $\begin{array}{l}\text { menor facilidad, necesidad de } \\
\text { arreglar las convexidades del } \\
\text { plano de percusión, y aquéllas } \\
\text { de la superficie de desbaste }\end{array}$ \\
\hline $\begin{array}{l}\text { Tajadas } \\
\text { sobre } \\
\text { yunque }\end{array}$ & $\begin{array}{l}\text { > sub-triangular a sub- } \\
\text { rectangular, regular en } \\
\text { cada núcleo }\end{array}$ & $\begin{array}{l}\text { regularmente } \\
\text { en cuña }\end{array}$ & grande & - & fácil \\
\hline $\begin{array}{l}\text { Unipolar } \\
\text { secante }\end{array}$ & $\begin{array}{l}\text { > ovoidal, sub- } \\
\text { cuadrado, sub- } \\
\text { rectangular, regular en } \\
\text { cada núcleo }\end{array}$ & $\begin{array}{l}\text { ¿Regular y } \\
\text { espesa? }\end{array}$ & pequeña & $\begin{array}{l}\text { lascas, excepto } \\
\text { un caso de } \\
\text { tendencia } \\
\text { laminar }\end{array}$ & $\begin{array}{l}\text { fácil, posible necesidad de } \\
\text { arreglar el plano de percusión }\end{array}$ \\
\hline Discoideo & $\begin{array}{l}\text { > sub-triangular a sub- } \\
\text { rectangular, irregular }\end{array}$ & irregular & $\begin{array}{l}\text { mediana a } \\
\text { pequeña }\end{array}$ & - & fácil \\
\hline
\end{tabular}


(materia prima), las elecciones deben expresarse en términos de dificultades o elecciones culturales (económicos, funcionales, etc.).

Por último, las diferencias de volumen útil de los núcleos en cada esquema conceptual no se discutieron debido al gran número de parámetros posibles. Lo que dificulta la comparación entre los cuatro sistemas de desbaste. Sin embargo, se recuerda que, en el marco de otros estudios, se estableció que el método Levallois representa una producción limitada a una parte del núcleo (una superficie), comparado al desbaste discoideo que posee una capacidad de producción basada en la totalidad del volumen (Boëda 1994: 266).

\section{DISCUSIÓN}

\section{Cadenas operativas y estrategias tecno-económicas}

La interpretación cultural de la información proporcionada por el estudio tecnológico de la Colección Cabo San Vicente I es difícil debido a las condiciones de recolección de estos vestigios (parcial y selectiva) y la complejidad de los sitios, generalmente erosionados, del litoral norte de Tierra del Fuego. Además, en el marco de este estudio, se abordó solamente el análisis de los núcleos.

Un concepto básico a ser considerado es el de cadena operatoria, concepto que permite explicitar los elementos constitutivos y las interrelaciones tecnológicas (sensu Lemonnier 1983), lo que abre perspectivas de comprensión de otros aspectos económicos y sociales de un grupo (Pigeot 1991:34, 43).

Este estudio se inscribe, además, en un marco cronológico mal definido. No obstante partiremos del supuesto de que los sistemas de desbaste descritos son esquemas operatorios que estuvieron vigentes de manera contemporánea. Es decir, suponemos que el conjunto estudiado resulta de la sumatoria de una sucesión de operaciones de importancia que incluyen los cuatro métodos y no una organización diacrónica de los métodos de desbaste descritos. Esta posible coexistencia de los métodos de desbaste puede ser apoyada por dos observaciones:

- Las producciones obtenidas por medio de los 4 métodos presentan características diferentes. No son intercambiables y representan actividades de producción complementarias, por lo que es lógico pensar que estarían operando de manera coetánea.

- El sitio Cabo San Vicente fue probablemente utilizado en forma recurrente durante el Holoceno reciente (presencia de tres métodos de desbaste en la terraza inferior). Esto, al menos, es el reflejo de un conocimiento de los recursos y de una práctica adquirida en un contexto cultural, y permite suponer que se efectuaron actividades similares durante las reiteradas ocupaciones de este lugar.

La identificación de estos métodos de producción de lascas, y los conceptos referidos anteriormente, nos llevan a cuestionar las distintas posibilidades de interpretación del registro, sus implicancias tecno-económicas, su relación con otros aspectos culturales y sociales. Pero, primero, quisiera trabajar los resultados desde la perspectiva de la o las cadenas operatorias involucradas.

\section{La adquisición}

$\mathrm{Al}$ intentar comenzar por la primera cadena, una de las más accesibles, se puede concluir que hay un suministro local de materias primas líticas. La disponibilidad de los guijarros en la costa podría ser una de las atracciones de las localidades litorales de Tierra del Fuego ${ }^{34}$, en paralelo a los recursos de fauna marina y a las mejores condiciones climáticas con respecto a las regiones interiores, debido a la influencia del mar, especialmente en temporada invernal.

Las características de esta fuente de materias primas líticas son explicadas por su origen en depósitos fluvio-glaciares, eventualmente alterados por el mar. Están constituidos por un conjunto de rocas variadas. Los bloques elegidos muestran las elecciones efectuadas en el marco de lo disponible. Pero no se conocen las dimensiones, formas, y proporciones/cantidades. En este sentido, no es posible evaluar la inversión en tiempo y energía necesarios para la selección de los nódulos utilizados efectivamente. Esto genera, igualmente, un problema al intentar explicar el elevado número de reclamaciones detectadas, en términos de una falta de restricciones en la disponibilidad y características de las materias primas.

34 Posiblemente los cantos rodados de origen fluvio-glacial serían menos accesibles en las localidades interiores, debido a la mayor estabilidad de los procesos de sedimentación y de la cubierta vegetal. 
La primera etapa de aprovisionamiento es, entonces, la recolección de guijarros de la playa o de los depósitos de la terraza alta. Pero se observó también un suministro secundario de materias líticas, entre los vestigios mismos del yacimiento:

- El retomado de los núcleos integrados directamente a la cadena de producción (12 núcleos, $13 \%{ }^{35}$ ), o a la cadena de consumo/utilización (30 núcleos retomados como instrumentos retocados).

- El aprovisionamiento por reclamación o traspaso intencional de una parte de los núcleos de tajadas sobre yunque a otros métodos de desbaste. Este suministro ha sido inferido indirectamente por la presencia de negativos de extracciones con la técnica sobre yunque en los primeros gestos de los esquemas diacríticos de algunos de núcleos de desbaste Levallois y unipolar secante. Además, por un evidente déficit de núcleos de desbaste en tajadas sobre yunque en rocas de fractura concoidal, un dato no menor frente a la predominancia de estas rocas (versus rocas de tipo laja) entre los productos - raederas. Ante esta ausencia, se pueden avanzar algunas explicaciones: o se transportaron y abandonaron estos núcleos sobre rocas concoidales fuera del sitio, o estas piezas no se explotan completamente en el marco del método de desbaste en tajadas y algunas partes se han reintroducido en los esquemas operatorios de otros sistemas de desbaste observados a Cabo San Vicente (métodos Levallois y unipolar secante).

\section{La producción}

La producción de lascas es el tema central del presente estudio. En primer lugar, hemos demostrado la existencia de cuatro cadenas de desbaste, parcialmente vinculadas por su suministro y sus secuencias de reclamación. Estos métodos de desbaste son la materialización de conceptos (sensu Boëda 1994, para el concepto Levallois), entendidos como una imagen ideal que responde a los principios constitutivos preconcebidos del desarrollo tecnológico (Pigeot 1991: 44), más o menos elaborados y planificados como operaciones técnicas reiteradas (sensu Inizan et al. 1995).

35 Porcentaje calculado sobre un total de 94 núcleos analizados en detalle, excluyendo los indeterminados (Tabla 1).
Las cadenas de producción puestas en juego en Cabo San Vicente, y apoyadas por la reconstitución de los métodos de desbaste sobre la única base de los núcleos, se interpretaron a partir de un número de variantes (modos de explotación y gestión, reclamaciones). En este contexto queremos insertar la problemática de las estrategias tecnológicas, entendidas como parte de los procesos que se desarrollan para solucionar y responder de manera dinámica a situaciones cambiantes que dependen de la relación entre un grupo humano y su medio (Nelson 1991: 58). El debate sobre las estrategias tecnológicas está basado en la pertinencia de su articulación con el concepto de planificación. Para el estudio de las estrategias tecnológicas de cazadores recolectores prehistóricos utilizamos algunos conceptos extraídos de la arqueología americana: curation, expediency y opportunistic, como fueron definidos por Nelson:

- la estrategia de conservación o curation es una planificación anticipada de la preparación de los artefactos, en función de necesidades y problemas potenciales vinculados a su utilización o a su consumo futuro ${ }^{36}$;

- la estrategia expeditiva (expediency) se basa en la anticipación de la presencia de materiales y tiempo necesario para desarrollar las actividades y usos de los artefactos; es pues una planificación basada en condiciones previsibles ${ }^{37}$.

- el oportunismo no es una estrategia, es la adaptación inmediata a necesidades no planeadas, no anticipadas, que se producen en condiciones inmediatas y circunstanciales ${ }^{38}$.

Las estrategias tecnológicas así definidas no son excluyentes y pueden considerarse como estrategias complementarias en un continuo de tipos de comportamiento que van desde acciones muy planeadas a respuestas inmediatas (Nelson 1991).

36 "Curation is a strategy of caring for tools and toolkits (...) preparation of raw materials in anticipation of inadequate conditions (materials, time, or facilities) for preparation at the time and place of use" (Nelson 1991: 62-63).

37 "Expediency refers to minimized technological effort under conditions where time and place of use are highly predictable (...) anticipates the presence of sufficient materials and time" (Ibíd.: 64).

38 "...not planned, it is responsive to immediate, unanticipated conditions" (Ibíd.: 65). 
El caso de Cabo San Vicente es muy coherente con una estrategia tecnológica expeditiva, donde las actividades y la ocupación de la costa se planean cerca de las materias primas y los lugares de almacenamiento (el sitio mismo). La preparación de los núcleos y la existencia de métodos de producción elaborados son, en efecto, argumentos en favor de esta planificación de las actividades de talla (más bien que de respuestas oportunistas). Además, se puede suponer una ausencia de estrés temporal en tanto los recursos son predecibles e inmóviles. Por último, la utilización frecuente y el retorno al mismo lugar están evidenciados por la extensión del lugar y el palimpsesto de ocupaciones.

El predominio de una estrategia expeditiva de gestión de los núcleos no excluye, sin embargo, el desarrollo posterior de estrategias de conservación, por ejemplo la producción de soportes (lascas) específicos destinados a transportarse a otra parte. Pero esta cuestión supera las posibilidades de interpretación de este estudio y deberá reconsiderarse en nuevos trabajos de terreno y en el análisis del resto de la colección (no sólo los núcleos).

$¿$ En el marco de esta estrategia expeditiva, cómo se planea la producción a Cabo San Vicente? Para discutir esta cuestión, se debe retornar a los métodos de desbaste y su producción. Anteriormente se indicó que las características de los productos y la recurrencia de su producción difieren en cada sistema de desbaste. Estamos hipotéticamente pues en una producción de soportes diferenciales (Perlès 1991), aspecto que deberá contrastarse con un futuro estudio detallado de los instrumentos de la Colección Cabo San Vicente, para responder cuestiones como la posible funcionalidad diferencial de estos soportes y su relación con distintas o una misma de las tradiciones y unidades culturales conocidas para Tierra del Fuego.

Las estrategias tecnológicas descritas pueden, también, ser estudiadas a partir de los tipos de artefactos y la distribución espacial de las actividades (sensu Nelson 1991). En la gestión de los métodos Levallois de Cabo San Vicente, el método más representado y rico del sitio, se puede ver que bajo la diversidad de los modos de explotación y las modalidades existe una intención de favorecer un diseño versátil o polivalente de núcleo (versatile design,
Ibíd). Un diseño versátil se basa en la presencia de un artefacto (núcleo) planeado para ser funcional en circunstancias variables, a partir del mantenimiento de una forma (criterios estructurantes del método) que permite una adecuación a necesidades diferentes (adaptado de Nelson 1991). En el caso del método Levallois aplicado en San Vicente, la producción consiste en lascas grandes, alargadas, medianas o pequeñas, más o menos finas, pero regulares y recurrentes. Esta polivalencia ${ }^{39}$ podría incluir también la gestión de las extracciones predeterminantes secantes de la modalidad asimétrica simplificada, y algunos otros casos de lascas predeterminantes semi-extendidas. Sigue planteándose la cuestión de la jerarquía de estos productos, según su grado de planificación: productos primarios, secundarios, subproductos, etc.; y según su pertinencia para la construcción de las grandes clases de herramientas (raederas, cuchillos, raspadores, etc.). Por el momento estamos solamente en posición de formular la hipótesis de una economía de desbaste basada en el concepto de desbaste Levallois a Cabo San Vicente (sensu Perlès 1991).

\section{Cuestiones de tradición cultural}

En síntesis, quisiéramos retomar algunas implicaciones de los conceptos anteriormente señalados, en el marco del concepto de tradición cultural, entendido como una visión diacrónica del sistema cultural:

- la gestión de los métodos de desbaste (producción de soportes) y su aprendizaje (conocimientos transmitidos de generación en generación) atestiguados por la alta frecuencia de los métodos de desbaste con predeterminación (sensu Inizan et al. 1995);

- el empleo de estrategias tecnológicas expeditivas; $y$

- una posible economía de desbaste Levallois.

Todos estos elementos de caracterización de los comportamientos tecnológicos formarían parte del subsistema tecnológico de los grupos prehistóricos de Tierra de Fuego. En el marco de

39 Este concepto se opone en parte al de flexibilidad, que incluye un diseño adecuado a una variedad de funciones obtenidas a partir de cambios formales (criterios estructurantes). 
futuros estudios, se buscará comprender mejor estos comportamientos técnicos, en particular, la interrelación de los elementos (objetos, proceso, conocimientos) que definen las técnicas de producción de soportes (sensu Lemonnier 1983). Las implicancias de estos comportamientos técnicos deberán también preverse más ampliamente: a partir de los elementos económicos, como el suministro de las materias primas, la disponibilidad de fauna terrestre y marítima; y de los aspectos sociales, como la organización y la recurrencia del modelo de utilización del espacio costero, el modelo de organización del grupo, etc.

Uno de los aspectos que afectan como una necesidad inmediata es la obtención de información comparable en otras localidades de la isla grande de Tierra del Fuego (la costa, el interior y la zona boscosa), y una precisión del marco cronológico. Una mejor comprensión de este sistema técnico pasa también por el estudio de otros aspectos de la industria, específicamente los instrumentos de estos cazadores prehistóricos. Finalmente puede preguntarse cuál es la relación entre estos comportamientos técnicos con los complejos culturales definidos como Selk'nam o Pre-Selk'nam, y otras unidades culturales que han sido genéricamente tratadas en investigaciones anteriores, como por ejemplo, el equivalente al período IV de Bird en Patagonia (Borrero et al. 1981; Massone et al. 1993).

\section{CONCLUSIONES}

Los resultados de este estudio permitieron avanzar en el conocimiento de los sistemas de desbaste utilizados por los grupos de cazadores terrestres que vivieron en la isla de Tierra del Fuego durante el Holoceno tardío. Se estudiaron cuatro métodos, uno de los cuales ya había sido descrito (Vallin 1992, Nami 1992). Sin embargo, ninguno dio lugar a estudios detallados sobre los esquemas operatorios puestos en obra y su variabilidad.

En general, a Cabo San Vicente I, los métodos de desbaste de lascas muestran un grado de elaboración y planificación escasamente registrado en el marco de los estudios arqueológicos existentes y de la información etnográfica conocida.

Las conclusiones de este estudio permitieron elaborar hipótesis y un panorama del modelo de utilización del litoral basadas en:
- la existencia de cuatro cadenas de desbaste, parcialmente vinculadas por su suministro y secuencias de reclamación;

- la reconstitución de una estrategia tecnológica expeditiva, donde se planean las actividades y el empleo de la costa;

- una economía de desbaste basada en el concepto Levallois y su carácter versátil o polivalente, considerándolo como un método de producción integrado de soportes diferenciales.

Estos aspectos propuestos, son elementos pertinentes para futuros debates sobre las tradiciones culturales fueguinas, sin embargo, estos resultados están basados en el estudio parcial de una colección procedente de un único lugar, mal ubicado cronológicamente. Será necesario, confirmar esta información y precisarla a través de otros estudios.

Las perspectivas previsibles para futuras investigaciones son: la mejora del marco cronológico de estos hallazgos tecnológicos, una mejor caracterización de los recursos líticos por localidad, el estudio de otros casos para discutir mejor la diversidad de los métodos de desbaste y las estrategias tecnológicas aplicadas, y de su importancia regional. También sería necesaria una investigación espacial más amplia, con el fin de completar nuestros conocimientos sobre las cadenas operatorias y evaluar la organización tecnológica en otros sitios. El descubrimiento de lugares y colecciones adecuadas para aplicar una metodología de remontajes podría ser una contribución capital en la evaluación de las intenciones de los métodos elegidos, y para explicar su variabilidad (sensu Pigeot 1991).

\section{AGRADECIMIENTOS}

Este estudio fue realizado en el marco del Proyecto FONDECYT 1020004 "Las Ballenas en el Mundo Selk'nam: un enfoque desde la arqueología y otras disciplinas, en el norte de Tierra del Fuego". Además, comprometen nuestra gratitud Dominique Legoupil, Nicole Pigeot, Marianne Christensen, Eric Boëda, Jacques Pelegrin, Marie France Faubert y Catherine Breux-Delmas en París, y en Chile, Mauricio Massone, Alfredo Prieto, Mateo Martinic, Pedro Cárdenas, Fabiana Martin y Manuel San Román. 


\section{BIBLIOGRAFÍA}

BOËDA, E. 1984. Méthode d'étude d'un nucleus Levallois à éclat préférentiel. Cahiers de Geographie Physique 5:95-133.

1994. Le concept Levallois: variabilité des méthodes. Monographie du CRA n ${ }^{\circ}$. CNRS Éditions, Paris.

BOËDA, E. y J. PELEGRIN. 1979-80. Approche technologique du nucleus Levallois a éclat. Etudes Préhistoriques $15: 41-48$.

BORRERO, L. A., M. CASIRAGHI y M. I. HERNÁNDEZ. 1981. Arqueología del Norte de la Isla Grande de Tierra del Fuego. Museo Territorial - Tierra del Fuego Año I(Julio):3-23.

BRÉZILLON, M. 1983. La Dénomination des objets de pierre taillée. IVe Supplément à "Gallia Préhistoire". C.N.R.S., Paris.

BRIDGES, L. 2000 [1948]. El último confín de la Tierra. Editorial Sudamericana, Buenos Aires.

CHAPMAN, A. 1977. Economía de los Selk'nam de Tierra del Fuego. Journal de la Société des Américanistes LXIV:135-148.

CLAPPERTON, C. 1992. La Última Glaciación y Deglaciación en el Estrecho de Magallanes: implicaciones para el poblamiento de Tierra del Fuego. Anales del Instituto de la Patagonia, Serie Ciencias Humanas 21:113-128.

DE MURO, S., A. DI GRANDE y A. BRAMBATI. 1996. Distribuzione dei terrazzi marini e transizionali (Olocene) e carta geomorfologica della fascia costiera della Península Juan Mazía - Tierra del Fuego Stretto di Magellano - Cile. Italian Journal of Quaternary Sciences 9 (1).(Trabajo presentado al Congreso "Il ruolo della Geomorfología nello studio della Geologia del cuaternario". Napoli Italia, Il Cuaternario. En carta geomorfológica.).

FRANCO, N. y L. A. BORRERO. 1999. Metodología de análisis de la estructura regional de recursos líticos. En En los Tres Reinos: prácticas de recolección en el Cono Sur de América, edited by C. M. A. K. y. P. M. V. Aschero. Instituto de Arqueología y Museo, Universidad Nacional de Tucumán.

INIZAN, M.-L., M. REDURON, H. ROCHE y J. TIXIER. 1995. Technologie de la Pierre Taillée 4. CREP (Cercle de Recherches et d'Études Préhistoriques, CNRS), Meudon.

JACKSON, D. 2002. Los instrumentos líticos de los primeros cazadores de Tierra del Fuego. Colección Ensayos y Estudios. Ril editores, Santiago, Chile.

LAMING-EMPERAIRE, A. 1959. Missions archéologiques J. Emperaire et A. Laming en Amerique du Sud. 19511959, pp. 4.

1959-1960. Inventaire des caisses envoyées à Paris, à Avallon, à Santiago.

1972. Pêcheurs des archipels et chasseurs des pampas. Objets et Mondes 12(2):167-184.

LEGOUPIL, D. 2003. Cazadores-Recolectores de Ponsonby (Patagonia austral) y su paleoambiente desde VI al III milenio A.C. Universidad de Magallanes ed. MAGALLANIA Vol. 31, número especial, Punta Arenas.

LEMONNIER, P. 1983. L'Etude des systemes techniques, une urgence en Technologie Culturelle. Techniques et Culture 2:11-34.
1991 De la culture matérielle à la culture? Ethnologie des techniques et Préhistoire. En 25 ans d'études technologiques en Préhistoire, edited by E. APDCA, pp. 15-20. XIe Rencontres Internationales d'Archéologie et d'Histoire d'Antibes, Juan-les-Pins.

LEROI-GOURHAN, A. 1943. Evolution et techniques I: l'homme et la matière. Albin Michel (reeditado en 1971), Paris.

1988. Dictionnaire de la Préhistoire. Presses Universitaires de France (PUF), Paris.

MASSONE, M. 1982. Cultura Selk'nam (Ona). Departamento de Extensión Cultural del Ministerio de Educación, Santiago.

MASSONE, M. 2004. Prospección arqueológica en Punta Catalina, Bahía Lomas y Bahía Lee. Informe de avance, $2^{\circ}$ año, proyecto FONDECYT 1020004, pp. 13.

MASSONE, M., D. JACKSON y A. PRIETO. 1993. Perspectiva arqueológica de los Selk'nam. Editorial Universitaria, Santiago, Chile.

NAMI, H. 1988. Arqueología experimental, tecnología, artefactos bifaciales y modelos. Estado actual del conocimiento en Patagonia y Tierra del Fuego. Anales del Instituto de la Patagonia, Serie Ciencias Humanas 18:157-176.

1992. Noticia sobre la existencia de técnica "Levallois" en península Mitre, extremo sudoriental de Tierra del Fuego. Anales del Instituto de la Patagonia, Serie Ciencias Humanas 21:73-80.

1992-93. Observaciones sobre desechos de talla procedentes de las ocupaciones tempranas de Tres Arroyos (Tierra del Fuego, Chile). Anales del Instituto de la Patagonia, Serie Ciencias Humanas 22:175-180.

NELSON, M. 1991. The study of technological organization. In Archaeological Method and Theory, edited by M. Schiffer, pp. 57-100. University of Arizona Press, Tucson.

PERLÈS, C. 1991. Économie des matières premières et économie du débitage: deux conceptions opposées? In 25 ans d'études technologiques en Préhistoire, edited by E. APDCA, pp. 35-45. XIe Rencontres Internationales d'Archéologie et d'Histoire d'Antibes, Juan-les-Pins.

PIGEOT, N. 1991. Entre Nature et Culture. Valeur heuristique de la technologie lithique par des approches systémiques et cognitives, pp. 186, Paris.

2003 L'Économie de la taille de la pierre. In Cazadores-Recolectores de Ponsonby (Patagonia austral) y su paleoambiente desde VI al III milenio A.C., edited by D. Legoupil, pp. 117-164. Universidad de Magallanes ed. MAGALLANIA Vol. 31, número especial, Punta Arenas.

RATTO, N. y M. F. GARCÍA. 1996. Disponibilidad y aprovisionamiento de materias primas líticas: muestreo piloto en sectores de la costa norte de Tierra del Fuego (Argentina). Arqueología 6:223-263.

SCHIFFER, M. 1987. Formativa processes of the archaeological record. University of Utah Press, Salt Lake City.

SCHLANGER, N. 2005. "Suivre les gestes, éclat par áclat" - la chaîne opératoire d'André Leroi-Gourhan. En Autour de l'homme: contexte et actualité d'André Leroi-Gourhan, edited by N. Schlanger, pp. 2-25, Paris.

VALLIN, L. 1992. De l'intérêt d'une recherche sur les formes predeterminées de débitage dans l'extrême-sud américain, pp. 10, Lille. MS. 